NBER WORKING PAPER SERIES

\title{
INDIVIDUAL VS. SOCIAL MOTIVES IN IDENTITY CHOICE: THEORY AND EVIDENCE FROM CHINA
}

\author{
Ruixue Jia \\ Torsten Persson \\ Working Paper 26008 \\ http://www.nber.org/papers/w26008 \\ NATIONAL BUREAU OF ECONOMIC RESEARCH \\ 1050 Massachusetts Avenue \\ Cambridge, MA 02138 \\ June 2019
}

We are grateful to Paola Giuliano, anonymous referees, Roland Benabou, Paul Collier, Gerard Roland, Jean Tirole, Giorgio Topa, Alessandra Voena, Fabrizio Zilibotti, and participants in seminars at CIFAR, NBER, UCSD, LSE/UCL, Harvard, Maryland, Michigan, Oxford, Tsinghua, INSEAD, Tolouse and Yale for helpful comments. We would like to thank CIFAR, the ERC, and the Torsten and Ragnar Soderberg Foundations for financial support. Finally, we are grateful to Loren Brandt and Lena Edlund for sharing some data. The views expressed herein are those of the authors and do not necessarily reflect the views of the National Bureau of Economic Research.

NBER working papers are circulated for discussion and comment purposes. They have not been peer-reviewed or been subject to the review by the NBER Board of Directors that accompanies official NBER publications.

(C) 2019 by Ruixue Jia and Torsten Persson. All rights reserved. Short sections of text, not to exceed two paragraphs, may be quoted without explicit permission provided that full credit, including $(\odot$ notice, is given to the source. 
Individual vs. Social Motives in Identity Choice: Theory and Evidence from China

Ruixue Jia and Torsten Persson

NBER Working Paper No. 26008

June 2019

JEL No. D01,D02,H1,J1,J13

\begin{abstract}
$\underline{\text { ABSTRACT }}$
The same government policy that incentivizes individuals to make a certain choice can have different effects across groups due to the existence of social norms. In this paper, we study how Chinese ethnic policies that give material benefits to minorities affect ethnicity choices for children in ethnically mixed marriages. We document that, on average, such policies increase the propensity of choosing minority status for the children. Meanwhile, responses to the same policies differ widely across localities, suggesting that social norms may be important. We formalize the ethnic identity choice in a simple framework, which highlights the interaction of material benefits stemming from the ethnic policies, identity costs associated with breaking the norms of following the father's ethnicity, and social reputations altering the importance of identity costs. This framework predicts that ethnic policies should increase the propensity of breaking the norm (i.e., following the mother's ethnicity) in localities where more families follow the norm. We find support for this prediction in microdata from multiple census waves, and show that a number of alternative explanations can be ruled out. More broadly, our study serves as evidence about the interplay of individual and social motivates in shaping policy consequences, as well as evidence on the determinants of identity choice.
\end{abstract}

\author{
Ruixue Jia \\ School of Global Policy and Strategy \\ University of California at San Diego \\ 9500 Gilman Drive \#0519 \\ La Jolla, CA 92093 \\ and NBER \\ rxjia@ucsd.edu \\ Torsten Persson \\ Torsten and Ragnar Soderberg Chair in Economic Sci \\ Institute for International Economic Studies \\ Stockholm University \\ SE-106 91 Stockholm \\ SWEDEN \\ and NBER \\ Torsten.Persson@iies.su.se
}

A data appendix is available at http://www.nber.org/data-appendix/w26008 


\section{Introduction}

The same government policy that incentivizes individuals to make a certain choice can have different effects across groups because of differential social motives. When would social motives amplify or mitigate the effects of policy interventions? This question is relevant for understanding the consequences of many policies, ranging from those that fight tax evasion to those that encourage political participation. In this paper, we study the question in the context of ethnicity choices in China. We formalize the interaction of individual and social motives in a simple model, and confront the model predictions with microdata. While our results are certainly quite specific to ethnic choices in China, they speak to a general question how the interplay between individual and social motives shapes the consequences of government policies. They also speak to the determinants of identity choice in other contexts.

Our empirical question is how material motives entailed in government policies, individual attitudes, and social motives jointly shape ethnic choices. China is an interesting testing ground to study such choices. First, it is a multiethnic society with 55 officially recognized ethnicities beyond the dominant Han (about 91.5 percent of the population). Second, mixed ethnic couples are free to choose whichever of their two ethnicities for their children at birth, and we observe such choices at the individual level in China's microdata. Third, the government has given policy favors to minorities in the areas of family planning and education that vary by province. While these policies may not be intended to encourage parents to choose minority status for their children, they do create material incentives to do so. Finally, the undisputed social norm in China's patriarchal society is to choose the father's ethnicity for the children. These four features allow us to study empirically how the interplay between social stigma and honor modifies the effects of changing material motives on ethnic choices.

For convenience, we refer to a mixed couple with a Han man and a minority woman as Han-minority and one with a minority man and a Han woman as minority-Han. To discipline our theoretical analysis, we start out from two facts on the ethnicity of children, which stand out in both aggregate and individual-level data: (1) the propensity of breaking the social norm of following the father's ethnicity - i.e., the share of children that instead follows the mother's ethnicity - is much higher in Han-minority families than in minority-Han families; and (2) the propensity of breaking the norms is increasing in Han-minority families after 1980, in tune with policy changes related to minority status. On top of these two facts, the extent of social-norm breaking amongst Han-minority families differs widely across localities (a closer account for these facts appears in Section 2).

Motivated by these facts, our theoretical analysis exploits a framework first suggested by Benabou and Tirole (2011). A key feature of this framework is that it allows for both complementarity and substitutability in individual decisions. In our setting, mixed couples make decisions on their children's ethnicity based on three interacting motives: material benefits (from policies favoring minorities), individual intrinsic costs (from picking an ethnicity against 
the social norm), and social reputations (depending on choices by other mixed couples in a peer group). For instance, a Han-minority family that chooses minority status for their child do obtain ethnic-policy favors, but suffer the intrinsic cost of breaking the norm. Meanwhile, the intrinsic cost gets amplified or mitigated by the social-reputation concerns. These concerns reflect a race between social honor (when following the ethnicity norm) and social stigma (when breaking the ethnicity norm).

Having discussed how the model relates to the facts mentioned above, we derive new predictions that can be empirically tested with individual-level census data. The key prediction is that the propensity to break the social norm - by giving the child in a Han minority family the mother's ethnicity - should be higher in localities where concerns for social stigma dominate those for social honor. Empirically, the relative importance of social stigma versus social honor can be proxied by the shares of mixed couples who follow and break the norms: when a small share breaks the norms, the stigma effect dominates the honor effect. Moreover, our model implies a nonlinear rather than a linear empirical specification in the share of mixed couples who break the norm. As a stricter test of our model, we derive an additional prediction on the non-linear effect in different quantiles, which is also confronted with data.

Consistent with our model predictions, the ethnicity of children in minority-Han families varies little in the data. Therefore, our empirical focus is on the ethnicity of children chosen by Han-minority families. To test the key prediction, we exploit the variation across around 300 prefectures (the administrative units one step below the province level) in the share of such families that break the social norm by giving the mother's identity to their children.

There are at least three empirical challenges to carry out the empirical tests. One is how to measure the material benefit of policies favoring minorities. Since ethnic policies appear in a bundle of provincial regulations, it is not straightforward to quantify their regional variation over time. To ensure that our results are robust, we use three alternative measures: rollout of the one-child policy, additional fertility rates for minorities (relative to Han), and additional scores for minorities in college-entrance exams. These policies vary by law at the province level. Of course, this does not rule out variation at more local levels (e.g., across prefectures) due to different implementation of the same law. However, our focus is on how ethnic policies shape people's ex ante choices. For this purpose, it seems reasonable to focus on legislated provincial-level policies.

A second challenge is that individual and aggregate ethnic choices in the relevant peer group may be simultaneous, creating an instance of the reflection problem (Manski 1993). To avoid this problem, we define the share of children that follow their mother's identity by the choices in cohorts born already in 1970-74 in the same prefecture - i.e., about a decade before the rollout of the one-child policy. This leads naturally to a difference-in-differences specification. The initial share becomes an ex ante classifier of social concerns, allowing us to compare the impacts of ethnic policies in prefectures with low vs. high 1970-74 norm-breaking shares. In addition 
to using the same prefecture as the peer group, we also employ alternative definitions, such as using county information (when it is available).

A third challenge is omitted variables. Ethnic policies may be correlated with other variables that also affect ethnic choices. We check for omitted variables in two ways. We show that pretrends are absent: changes in ethnic choices occur only after the implementation of the ethnic policies. On top of this, we collect a set of regional characteristics, allowing these to have different impacts on outcomes before and after the introduction of the ethnic policies - we then check if our estimates are stable when these characteristics are or are not considered.

Using individual census data from 1982, 1990, 2000, and 2005 (which can be linked via prefecture information), we document that policies that raise the material benefits of minority children do indeed trigger a higher propensity to choose minority children in Han-minority families. For instance, when measuring material benefits via the rollout of the one-child policy, we find that the minority share of children goes up by 7.8 percentage points (19 percent of the pre-policy probability). Estimates with the difference-in-differences specification confirm that the effect of ethnic policies is larger in prefectures with a share of norm-breakers below a certain cutoff. For example, with the one-child measure of material benefits, the increase in minority children is 10.3 (3.1) percentage points for prefectures where the share norm-breakers in the 1970-74 cohort is below (above) 50 percent. We also find support for the additional prediction of a non-linear effect in different quantiles.

The paper discusses in detail several theoretical and empirical alternative explanations for the results: different preference specifications, different definitions of social reputations or peer groups, changing bargaining power of women, the minority-population share diluting material benefits or inducing social conflict, a kind of censoring, and changes in the number of children. While we find that some of these alternatives may contribute to the changing ethnicity of children to mixed couples, none of them alters our main empirical results on the interaction between individual and social motives.

Our study contributes to several lines of research. First, it complements a burgeoning literature on the interaction of individual and social motives, where social-image concerns are critical (e.g., Bursztyn et al. 2014, Bursztyn and Jensen 2017, Cantoni et al. 2018, Karing 2019). ${ }^{1}$ Many of these studies are done in experimental settings, while ours analyzes large-scale observational data.

Second, our study provides a novel perspective on identity choice. Sociologists and political scientists have contributed to the understanding of ethnic identity earlier than economists. While that literature is too large to survey here, one example is the pioneering research by Bates (1974) and Vail (1989) on the role of ethnic identity and tribalism in Africa. Existing economic studies suggest different determinants of identity. Some of them show how social and intrinsic motives

\footnotetext{
${ }^{1}$ There is also evidence from experimental settings that often focuses on either complementarity or substitutability (e.g., Gneezy and Rustichini 2000, Fehr and List 2004, Ariely, Bracha and Meier 2009 among others). See Gneezy, Meier and Rey-Biel (2011) for an overview.
} 
can support persistent choices (Akerlof and Kranton 2000, Bisin and Verdier 2000, Bisin, Topa and Verdier 2001, Fernandez and Fogli 2006), while others show how material incentives can create individual motives for identity change (Botticini and Eckstein 2007, Cassan 2015, Nix and Qian 2015). More recently, Fouka (2019) and Atkin, Colson-Sihra and Shayo (2019) analyze how social and economic factors shape identity choice using conceptual frameworks different from ours.

While understanding the complex interaction between different motives certainly requires multiple frameworks, we believe our method can be applied to a wide set of individual choices in the economic, political or social arena, where individual and social motives both play a substantial role. Subsequent to the first version of this paper, Besley, Jensen and Persson (2018) use an extension of the Benabou-Tirole model to derive predictions for an empirical study of the evasion from local property taxes in the UK. But these authors focus on other issues and use council-level rather than individual data. Joensen and Skyt Nielsen (2015) also use the Benabou-Tirole model to set up an empirical analysis based on individual data of the choice of Math and Science majors among girls and boys in Denmark. Chen (2016) exploits a similar framework to explain the extent to which the death penalty spurred absences in the British military during World War I.

The next section of the paper presents several facts and describes the relevant institutional background to our study. Section 3 formulates our model and spells out its predictions. Section 4 discusses which Chinese data can be used to test them. Section 5 demonstrates empirically that the main theoretical predictions are consistent with these data. Section 6 discusses alternative explanations for the patterns in the data and whether these explanations drive our main result. Section 7 provides a brief conclusion. To save space, we relegate some additional modeling, tables, and figures to an Online Appendix.

\section{Background}

China has 56 ethnic groups, the dominant Han plus 55 minorities. As of 2000, the combined population of minority groups stood at about 106 million, 8.5 percent of the total mainland population. The 55 minority groups vary widely in size. With a population of more than 15 million in 2000 the Zhuang was the largest minority, and the Lhoha with only 2,965 the smallest. Minority groups also vary greatly in culture, spoken language and religious practice 53 minority groups speak languages of their own, 23 have their own written language, 10 groups are predominantly Muslim, and eight follow Tibetan Buddhism. 


\subsection{Salient facts on ethnic choices}

We now point at salient facts on the ethnicity of children in mixed couples, which we will use to discipline the theoretical analysis. ${ }^{2}$ The first fact is:

F1 The average share of children with their mother's ethnicity is much higher in Han-minority families than in minority-Han families. This indicates a higher propensity of breaking the social norm for Han-minority families.

Figure 1 panel (a) plots ethnicity shares over time in the aggregate data - by five-year birth cohorts - for the two types of mixed marriages. On average, the probabilities that children have their mother's ethnicity in minority-Han and Han-minority families are 6 and 47 percent, respectively. Naturally, these aggregate patterns can be confounded by regional characteristics and time trends. However, as discussed in Online Appendix A1, differences of the same magnitude hold also at the individual level, when we control for prefecture fixed effects, birth-year fixed effects, and province-specific trends (province fixed effects times birth year).

The second fact is:

F2 The propensity to break the social norm (i.e., the share of children with their mother's ethnicity) is increasing in Han-minority families after 1980.

This pattern is clearly shown in panel (a) of Figure 1. At the aggregate level, the average share of children in Han-minority families with their mother's (minority) ethnicity is 41 percent in cohorts born before 1980, but 49 percent cohorts born after 1980, indicating a higher propensity of breaking the norms. Panel (b) shows that this pattern also holds at the individual level (after controlling for prefecture fixed effects and province-specific trends). Differently, we observe little change in the choices by minority-Han families. In those families, the aggregate-level data suggests a slight increase in the average share of children with their mother's (Han) ethnicity, but this change is not significant in the individual-level data once we control for province-specific trends (see the shaded area in panel (b)). If anything, the individual-level trend is weakly decreasing until the 1990s.

On top of these basic facts, we also find wide variation across prefectures in the propensity for Han-minority families to break the social norm. Figure 2 plots the shares of children with their mother's ethnicity across prefectures in the two types of mixed families with children in the 1970-74 cohort. These shares have a mean around 0.39 and a standard deviation of 0.33 for Han-minority families. By contrast, the variation is much smaller for minority-Han families.

\footnotetext{
${ }^{2}$ We use the 1982, 1990, 2000 censuses and the 2005 mini-census. Our analysis focuses on the children born between 1970 and 2005. See Section 4 for more detail on data structure and availability.
} 


\subsection{Benefits and Costs of Minority Children}

Anecdotal evidence Little research exists on ethnic choices for children in China. However, one finds numerous discussions online among parents, which reflect the motives for alternative ethnicity choices for their children.

One example of a suggestive discussion [in our own translation from Chinese] appears at the website babytree.com - see Online Appendix A2 for the original discussions:

Anonymous asked: "If the father is a Han and the mother is a minority, could the child be a minority?"

Linyibaobeixuan answered: "Generally should follow the father's. But following the mother's has benefits of ethnic favors."

Yuer2011 answered: "The child usually follows the father's ethnicity. It is also fine if you insist on following the mother's."

Sankouzhijiatu answered: "The child should follow the father's ethnicity. Only the children of a live-in husband will follow the mother's."

Xixi1011 answered: "You can follow the mother's. A minority has the option of having a second child."

This dialogue suggests that material benefits due to ethnic policies - especially the option for a minority child of having more than one child as an adult - are considered motives to adopt the mother's ethnicity in Han-minority families. The costs of having a minority child are primarily social and intrinsic: the social norm is that children adopt the fathers' ethnicity and the opposite choice imposes costs on a father. For instance, a Han man with a minority child may be stigmatized - as the wife usually goes to live in the husband's family, only lower-status men will consider becoming live-in husbands, known as "uxorilocal marriage" in social anthropology.

This first example thus illustrates the stigma side of social reputations, in that men with children of a different ethnicity can be considered of low social status. Another illustrative

discussion [also in our own translation from Chinese] is found at the website jzb.com (jzb means parents' helper in Chinese) - see Online Appendix A2 for the original discussions:

Zhongermen said: "I went to register the birth of my child a while ago. I am a Han man and my wife is a minority. I told the police that I want my child to be a Han. The police kindly suggested that I should choose minority for the child. She said that one score lower implies an extra playground of competitors in the highschool entrance exam and that I should be responsible for my child's future. But I insisted on choosing Han in the end. I hope that my child's future will reply on his own ability, not ethnic favors."

fh2315 remarked: "Choosing minority is not a big deal if the minority does not practice religion." 
claetitia remarked: "Well, if you despise the ethnic favor for extra scores, minorities can at least have more children!"

Magua remarked: "I am a minority and my child follows my ethnicity. The reason is simple. Even though I belong to a minority group whose population size is large, I am proud of my ethnicity. So I hope that my child is also [proud of my ethnicity]. This has nothing to do with extra scores."

Once again, these arguments reflect the trade-off between material individual benefits and intrinsic or social motives. But this example illustrates the honor, rather than the stigma, side of social reputations. For instance, the Han man who starts the discussion feels honorable to assign his own ethnicity to his child despite the favors toward ethnic minorities. The first commentator suggest that the cost may be higher to adopt the mother's minority ethnicity when this is associated with religious practice. As already mentioned, our theoretical framework will allow for such interaction effects. The last commentator argues that he chooses his own ethnicity for his child because he is proud of his ethnicity and hopes the child will share this pride. Already mentioned, our theory will focus on the interplay between social stigma and social honor. Next, we describe the ethnic policies entailed in these discussions.

The choice of ethnicity No legal barriers exist for mixed marriages between any two ethnic groups. At the birth of a child, a mixed couple has to choose one of their own ethnicities for their children. The ethnic identity appears in almost every context, including the birth certificate and all the forms which have to be filled out at school. This information is particularly salient, when someone gets benefits due to his or her ethnicity status. This means that the chosen ethnicity can be considered public information to peers. As already suggested by the data, an ethnic choice is more than a label. If it were merely a label, all parents would choose minority status in view of the preferential policies.

Minority identity brings both benefits and costs for the child, and hence indirectly for the parents. According to government regulation, couples with the same ethnicity cannot choose any other ethnicity for their children. As for switches later in life, children from mixed marriages can apply to change their ethnicity given at birth before the age of 20 . However, the applications have to be made by the parents for those younger than 18. Since these applications are costly and approval is uncertain, the impact of policy interventions on switches later in life should be much less important than the ethnicity choices by parents at birth. Unfortunately, no systematic data is available to shed light on this. As an indirect check, we examine the correlation of ethnicities by prefecture-birth year across censuses. For instance, the correlation for the 1982 and 1990 samples is around 0.96, suggesting that switching ethnicities do exist but cannot be very frequent. 
Benefits of minority children The benefit side reflects various policies. Since the beginning of the People's Republic of China (1949-), the government has introduced various benefits to ethnic minorities so as to promote positive Han-minority relationships. Such policies exist in three areas:

(i) Family planning. When family-planning policies started in the 1960s, minorities were more favorably treated than the Han majority. Over time, the treatment of different minorities has varied by region. As detailed in Section 4, family-planning policies became much more stringent in the years around 1980 with the implementation of the one-child policy, rendering the advantages of minorities more salient.

In our analysis, we use two measures: one is on the rollout of family-planning policies across provinces; the other is the completed fertility ratio of minority vs. Han mothers (aged 40 and above). Section 4 describes this measurement in detail.

(ii) Entrance to higher education. Since the restoration of entrance exams in 1977, minorities have enjoyed additional points in the exams deciding upon educational entries, especially to high school and college. These benefits also vary by province. In our analysis, we measure this benefit by average extra scores for minorities by province in the National College Entrance Exam. Once again, Section 4 details data and measurement.

(iii) Employment. The national ethnic policy states that minorities should have favorable treatment in employment. However, explicit benefits are rare. As minorities can be discriminated in employment, it is unclear that this policy would make people tend to choose minority identity for their children. For instance, Hasmath and Ho (2015) find that minorities perceive that they are disadvantaged in job search, even though estimated Han-minority wage differentials demonstrate little evidence for this.

Costs of minority children The cost side has two main aspects explained below:

(i) Discrimination. Minorities may face discrimination in the labor market, even when they have the same educational background as Han. However, two facts suggest that the material benefits discussed above are likely to dominate the potential discrimination costs in the labor market. First, in the anecdotal discussions, discrimination is never mentioned when parents make ethnicity choices for newborns. Second, almost all minority-Han couples choose minority ethnicity for their children - one would expect to see more Han children if discrimination was a dominant concern relative to patriarchal norms. In any case, our model below has a basic level of net material benefits, which can be positive or negative; what matters for our predictions is the increase in these net benefits in connection with family-planning and education policies. Our framework thus allows for the existence of discrimination.

(ii) Identity costs. As highlighted by the anecdotal discussions, a main disadvantage of having a minority child for Han-minority families is an identity cost, especially for Han fathers. In a patriarchal society such as China, children are expected to follow the ethnicity of the father. Additionally, the identity costs are likely affected by prevailing social norms and by the choices 
of relevant peer groups. Therefore, a Han man will face a trade-off between material benefits (on behalf of the child) and social status. By contrast, the problem for a minority father does not involve a trade off: having a child of his own ethnicity not only brings material benefits to the child, but also conforms to the prevalent social norm.

Given these considerations, our model in Section 3 incorporates three different motives: individual material benefits, intrinsic benefits or costs, and social reputations. We also build in the asymmetry for Han and minority men. Before presenting the model, we describe the patterns of mixed marriages which provide the context of ethnic choices for the children.

\subsection{Mixed Marriages and Demographics}

Besides ethnic choices, a few other demographic characteristics vary over time with familyplanning policies. First, the population share of minorities is increasing: from 8.7 percent for those born in 1970-74 to 10.1 percent for those born in 1990-1994. This is a consequence of the ethnic choices studied here, as well as different fertilities among Han and minorities. Second, family-planning policies raise male-to-female sex ratios and consequently affect the marriage market. For instance, the sex ratio goes up from 1.01 for those born in 1970-74 to 1.15 for those born in 1990-1994.

While we do not focus on the marriage-market consequences in this paper, these also respond to ethnic policies. For instance, the probability to marry a Han man for minority women born in 1940-44 (married in the 1960s) was 14 percent, whereas it went up to 21 percent for minority women born in 1970-74 (married in the 1990s). This hike is likely related to policies favoring minority children - no specific policy favors mixed marriages as such during the period we study, but the ethnic benefits to children do affect the relative value of entering into a Han-minority marriage vs. a Han-Han marriage. ${ }^{3}$

Later in our analysis, we will show that our findings are not affected by marriage patterns. Nevertheless, it is useful to know the prevalence of mixed marriages. In Online Appendix A3, we present descriptive patterns of the four possible types of marriages, as well as education and age differences between husband and wife. Compared with couples of the same ethnicity, education differences among mixed couples are slightly lower, suggesting a bit more assortative matching by education. Age differences between husband and wife do not differ substantively across marriage types. Among married couples that appear in our four censuses, 17 percent of minority men marry Han women, while 18 percent of minority women marry Han men. ${ }^{4}$

\footnotetext{
${ }^{3}$ Huang and Zhou (2016) argue that the one-child policy has raised the probability of mixed marriages in China due to the material benefits.

${ }^{4}$ This gender-ethnicity difference is much less striking than the corresponding difference in US black-white marriages, where 6 percent of black men marry white women while 2.9 percent of black women marry white men around 2000 (Fryer 2007).
} 


\section{Theory}

We employ the framework in Benabou and Tirole (2011) to model the ethnicity choice for children as a trade-off involving individual (material and intrinsic), as well as social (normsrelated) payoffs. The distinctive feature is that prevailing norms imply not only a social stain (stigma) when the norm is broken but also a social esteem (honor) when the norm is followed. As illustrated by the anecdotal discussions in Section 2, mixed couples choosing ethnicity for their children have both stigma and honor in mind. This framework allows us to analyze the interplay between the two, where individual behaviors can be either complements or substitutes, depending on the behavior of others.

As the main role of the model is to derive empirical predictions, we include only the prospective determinants of ethnicity choices that can be measured - or proxied - with some degree of confidence (see Section 4). The model is certainly highly stylized. However, it is not only consistent with the facts presented in Section 2, but it also yields additional and testable predictions. In particular, the model clearly predicts how material benefits and social motives interact, our main issue of interest.

\subsection{Setup}

Consider a region - a prefecture, to be concrete - with a continuum of households (couples) in a given cohort. There are two ethnicities $J \in\{H, M\}$, where $H$ denotes Han and $M$ minority. Children yield the same basic benefit $v$ for every household. Each household has a single binary decision to make: to break the norms by assigning mother's ethnicity for their child, $m=1$, or not, $m=0$. In line with China's social situation, we assume that (i) the choice primarily reflects the father's preferences (see Section 6 for a model of bargaining and related implications), and (ii) the socially acceptable choice is to pass on the fathers's ethnicity to the child. We focus on the decisions by mixed couples $(H, M)$ or $(M, H)$, where the first entry is the ethnicity of the father. (Non-mixed couples are obliged to pick their joint ethnicity for their child.)

Han-minority mixed couples Consider a typical $H, M$ couple. All such couples in the prefecture belong to the same peer group. They have a preference function

$$
u^{H, M}=v+(b-e(H)-\varepsilon) m+\mu E(\varepsilon \mid m)
$$

where $b$ is the net material individual benefit of having a minority child. This could differ across regions or time, due to different policies favoring minority children (recall Section 2). Further $e(H)+\varepsilon$, is the intrinsic individual cost of a child different from the father's ethnicity (recall Section 2). Its first component $e(H)$ is the average cost perceived by households when their child has different ethnicity than the Han father - this is common and deterministic to all peergroup members, but could differ across groups. The second component $\varepsilon$ captures the variation 
in intrinsic cost, the only source of household heterogeneity. We assume that $\varepsilon$ is distributed across couples with mean $E(\varepsilon)=0$, c.d.f. $G(\varepsilon)$, and continuous, differentiable, and single-peaked p.d.f. $g(\varepsilon)$. By these individual motives alone, households with high $\varepsilon$ would have a child with the father's Han ethnicity, while those with a low value would have a child with the mother's minority ethnicity.

The final term in (1) captures the social motive: the household's social reputation (or self image) - how the peer group views the mixed couple (or the couple views itself) - given its ethnicity decision. This assessment varies with the actions and the norms of the mixed couple's peer group, which explains the specification as a conditional expectation. Taken literally, the model assumes that the choices of $m$ are perfectly observable by everybody in the peer group. In reality, observability is realistic since the ethnic choice follows the child through life, as discussed in Section 2. The assumption can easily be relaxed to allow for stochastic observation - in that case, one part of parameter $\mu$ reflects the probability that $m$ is observed.

As high-value $\varepsilon$ households make the socially accepted choice, we assume that the household's social reputation is increasing in its "expected type" $E(\varepsilon \mid m)$, the conditional mean of $\varepsilon$ of those in the peer group who make the same choice as the couple does. Parameter $\mu$, is the relative weight on this social motive. (In the Online Appendix, we consider alternative preference structures without social reputations, as well as alternative formulations for the social reputations.)

It is useful to define the difference

$$
\Delta=E(\varepsilon \mid m=0)-E(\varepsilon \mid m=1) .
$$

The value of $\Delta$ is the couple's gain in social reputation within its peer group when it conforms to the social norm to give the father's (Han) ethnicity to the child. In the language of Benabou and Tirole (2011), the first term is the social honor of a child with the father's ethnicity - i.e., of making the socially accepted choice - and the second term is the social stigma of a child with the mother's ethnicity - i.e., of making the non-socially accepted choice.

An equilibrium cutoff rule With this notation, it follows from (1) and (2) that the mixed couple is indifferent about the child's identity when

$$
b-e(H)-\varepsilon_{H}^{*}=\mu \Delta\left(\varepsilon_{H}^{*}\right) .
$$

Since social reputations depend on how other couples in the peer group behave, this equality implicitly defines an equilibrium cutoff value $\varepsilon_{H}^{*}$. For the marginal couple, the net individual benefit of a child with the mother's ethnicity (the LHS) is equal to the gain in social reputation of a child with the father's ethnicity (the RHS). Children to couples with an $\varepsilon$ below $\varepsilon_{H}^{*}$ get the mother's ethnicity and those with an $\varepsilon$ above $\varepsilon_{H}^{*}$ get the father's ethnicity. Consequently, the 
share of children with the mother's (minority) ethnicity in the peer group is given by $G\left(\varepsilon_{H}^{*}\right)$. By $(3), \varepsilon_{H}^{*}$ is a function of $b, e$ and $\mu$. Given the cutoff rule, the equilibrium gain in social reputation becomes

$$
\Delta\left(\varepsilon_{H}^{*}\right)=E\left(\varepsilon \mid \varepsilon>\varepsilon_{H}^{*}\right)-E\left(\varepsilon \mid \varepsilon<\varepsilon_{H}^{*}\right)>0 .
$$

By definition of truncated means (of a mean-zero variable), the first term is always positive and the second term is always negative. Hence, $\Delta\left(\varepsilon_{H}^{*}\right)$ is always positive. By the results in Jewitt (2004), the single peak of $g$ implies that $\Delta$ has a unique interior minimum. ${ }^{5}$

Comparative statics From the cutoff condition (3), we can derive how the share of children with mother's ethnicity changes with material benefits of such children $b$. By the implicit function theorem, we have

$$
\frac{\partial G\left(\varepsilon_{H}^{*}(b, e, \mu)\right)}{\partial b}=g\left(\varepsilon_{H}^{*}(b, e, \mu)\right) \frac{1}{1+\mu \frac{d \Delta\left(\varepsilon_{H}^{*}(b, e, \mu)\right)}{d \varepsilon^{*}}}>0
$$

Higher material benefits for minorities raise the share of children with (the mother's) minority ethnicity: the density is positive and so is the "social multiplier" - if we follow Benabou and Tirole (2011) and assume that $1+\mu \frac{d \Delta\left(\varepsilon_{M}^{*}(b, e, \mu)\right)}{d \varepsilon^{*}}>0$ (which implies that $\mu$ is not large enough to create multiple equilibria). The social multiplier reflects the interaction between individual and social motives in the model and the properties of the comparative statics depend on the sign and size of $\frac{d \Delta\left(\varepsilon_{H}^{*}\right)}{d \varepsilon}$, i.e., how the gain in social reputation from a Han child changes with the behavior of others.

As $\varepsilon_{H}^{*}$ rises with $b$, more couples follow the mother's minority ethnicity. Then, both the honor and the stigma terms in (4) goes up in value. When more children get the mother's minority ethnicity (i.e., breaking the norm), this makes following the norm more honorable. At the same time, having a minority child becomes less stigmatizing. What matters for the sign of $\frac{d \Delta\left(\varepsilon_{H}^{*}\right)}{d \varepsilon}$ is whether the honor goes up by more or less than the stigma goes down ("goes down" here and below means that a negative number becomes closer to zero).

The race between honor and stigma Panel (a) of Figure 3 illustrates two different possibilities. Suppose first that $\varepsilon_{H}^{*}=-\epsilon<0$ in the left tail of the $\varepsilon$ distribution, so the share of minority children is small. In this case, the effect on the honor is relatively small, as this is the truncated mean of $\varepsilon$ in the whole distribution to the right of $-\epsilon$. But the effect on the stigma the truncated mean of $\varepsilon$ in the (green) tail to the left of $-\epsilon$ - is relatively large. As the stigma of a minority child goes down faster than the honor of a Han child goes up, the gain in social reputation from having a Han child goes down. That is $\frac{d \Delta\left(\varepsilon_{H}^{*}\right)}{d \varepsilon^{*}}<0$, so more people yet have minority children. In this case, the decisions of different couples are strategic complements and

\footnotetext{
${ }^{5}$ Note that, for the whole peer group, social reputation is like a zero-sum game: under a veil of ignorance about $\varepsilon$, the ex ante expected value of $\mu E(\varepsilon \mid m)$ is zero (as the unconditional mean of $\varepsilon$ is zero).
} 
the social multiplier is larger than 1.

The alternative equilibrium in Figure 3(a) has $\varepsilon_{H}^{*}=\epsilon>0$ in the right tail of the distribution, where many couples break the social norm and have minority children. In this case, the honor of a Han child - the truncated mean in the (red) tail to the right of $\epsilon$ - goes up faster than the stigma of a minority child goes down, so the gain in social reputation from having a Han child rises, which dampens the rise in the share of minority children. That is, $\frac{d \Delta\left(\varepsilon_{H}^{*}\right)}{d \varepsilon^{*}}>0$, decisions of different couples are strategic substitutes, and the social multiplier is smaller than 1.

Panel (b) of Figure 3 illustrates this race between honor and stigma in a numerical example with a symmetric distribution. It shows that both the honor of respecting the norm goes up and the stigma of breaking the norm goes down (its negative value comes closer to zero) with a higher $\varepsilon^{*}$ and that the (positive) honor always exceeds the (negative) stigma. Moreover, the honor goes up faster when many Han-minority couples have minority children, whereas the stigma falls faster when few couples have minority children. This difference generates the pattern in panel (c), where $\Delta\left(\varepsilon_{H}^{*}\right)$ decreases in $\varepsilon^{*}$ when few children among Han-minority families have the mother's ethnicity but increases in $\varepsilon^{*}$ when many such children have the mother's ethnicity.

Under a relatively mild assumption on the $\varepsilon$-distribution, the second derivative of $\Delta\left(\varepsilon_{H}^{*}\right)$ is everywhere positive $\frac{d^{2} \Delta\left(\varepsilon_{H}^{*}\right)}{d \varepsilon^{* 2}}>0$. Once we make that assumption, the multiplier monotonically decreases as the initial equilibrium $\varepsilon_{H}^{*}$ (and the share of children following mother's ethnicity) travels from low values to high values.

Minority-Han mixed couples In a $M, H$ mixed couple, the preference function analogous to (1) can be written:

$$
u^{M, H}=v+(1-m) b-m(e(M)+\varepsilon)+\mu E(\varepsilon \mid m)
$$

where $e(M)$ and $\varepsilon$ now represent the average and idiosyncratic intrinsic cost of having a child with the mother's ethnicity (Han in this case), as the socially acceptable choice is now to pass on minority identity to the child. We specifically assume that the distribution function $G$ for $\varepsilon$ and the weight on social reputation $\mu$ are the same in the two types of couples in the same locality. ${ }^{6}$

The $M, H$ couple will have a Han child when $-(e(M)+\varepsilon)+\mu E(\varepsilon \mid m=1)>b+\mu E(\varepsilon \mid$ $m=0)$. Defining the gain in social reputation in an analogous way as before - i.e., $\Delta$ is the honor of following the father's minority ethnicity, $\mu E(\varepsilon \mid m=0)$ minus the stigma of following the mother's Han ethnicity, $\mu E(\varepsilon \mid m=1)$ - we can write the indifference condition for a Han child as

\footnotetext{
${ }^{6}$ This is a strong assumption, although one can think of arguments why $\mu$, say, could be either higher or lower among minorities than majorities - the former may be more eager to fit in or more eager to preserve their identities. We do not pursue this issue further, however. The main argument is measurement: since proxies for $\mu$ and the distributions of $\varepsilon$ would be very hard to find in available data, theoretical predictions would be empirically empty.
} 


$$
-b-e(M)-\varepsilon_{M}^{*}=\mu \Delta\left(\varepsilon_{M}^{*}\right) .
$$

Thus, minority-Han households with $\varepsilon$ smaller (larger) than $\varepsilon_{M}^{*}$ will have Han (minority) children. Because $\Delta$ is always positive, it follows that $\varepsilon_{M}^{*}<0$. The share of children with the mother's Han ethnicity within this peer group is thus $G\left(\varepsilon_{M}^{*}\right)$.

In the same manner as for $H, M$ couples, we can derive the comparative statics for a change in $b$ to get:

$$
\frac{\partial G\left(\varepsilon_{M}^{*}(b, e, \mu)\right)}{\partial b}=-g\left(\varepsilon_{M}^{*}(b, e, \mu)\right) \frac{1}{1+\mu \frac{d \Delta\left(\varepsilon_{M}^{*}(b, e, \mu)\right)}{d \varepsilon^{*}}}<0
$$

\subsection{Consistency with Motivating Facts}

In this subsection, we show that the model is consistent with the facts presented in Section 2.

Choices across mixed marriages - Fact F1 In terms of the model, F1 requires that (in the majority of prefectures) $G\left(\varepsilon_{M}^{*}\right)<G\left(\varepsilon_{H}^{*}\right)$. This follows from (3) and (7) plus the fact that $1+\mu \frac{d \Delta}{d \varepsilon^{*}}>0$.

The intuition is straightforward: on average, minority men experience not only material benefits, but also intrinsic benefits and higher social reputation of a child with their own ethnicity. Compared to Han men, more of them thus choose their own identity for their children. Because $H, M$ mixed couples trade off material benefits against intrinsic and social reputation costs, they are more likely to cross the paternal ethnic cutoff.

The effect of material benefits - Fact F2 Expressions (5) and (8) show how the two types of couples react to an higher material benefits, $b$. These expressions reveal that higher $b$ raises the probability of a child with mother's ethnicity for Han-minority families, everything else equal, consistent with F2. By contrast, the model predicts an opposite pattern for minorityHan families. However, the probability to pick the mother's ethnicity is already very low, which leaves little variation to explore statistically.

Our model is thus consistent with facts F1 and F2. We now turn our interest to the new predictions from the model, which are the ones we will test empirically.

\subsection{Main Prediction}

Our most important prediction concerns the interaction between individual (material) motives and social motives. We focus on the effects on Han-minority families and state the model predictions in two alternative ways.

Comparing high and low initial cutpoints We first derive a testable prediction about the effects of a change in material benefits, depending on the initial equilibrium. Expression (5) says 
that material benefits are crowded in by social reputation - a social multiplier $\frac{1}{1+\mu \frac{d \Delta\left(\varepsilon_{H}^{*}(b, e, \mu)\right)}{d \varepsilon^{*}}}$ larger than 1 - when few Han-minority couples break the social norm and their choices are strategic complements $\left(\frac{d \Delta\left(\varepsilon_{H}^{*}(b, e, \mu)\right)}{d \varepsilon^{*}}<0\right)$. When many couples break the social norm and choices are strategic substitutes $\left(\frac{d \Delta\left(\varepsilon_{H}^{*}(b, e, \mu)\right)}{d \varepsilon^{*}}>0\right)$, the benefits are instead crowded out - a social multiplier smaller than 1 . This difference between crowding in with low shares of norm breakers, but crowding out with high shares of norm breakers is the essence of our model.

But the effect in (5) of a change in benefits also includes the density $g\left(\varepsilon_{H}^{*}\right)$ at the initial cutpoint. When considering this channel, we impose the condition that the distribution of $\varepsilon$ has (weakly) positive skew. ${ }^{7}$ Specifically, we assume that the median $\varepsilon_{50}$ (and the mean) of the distribution lies (weakly) to the right of the mode. Suppose we compare two prefectures with cutpoints at percentiles equidistant from - and not too far from - the median, i.e., $\varepsilon_{50+n}^{*}$ and $\varepsilon_{50-n}^{*}$. Because of the positive skew, we have $g\left(\varepsilon_{50-n}^{*}\right) \geq g\left(\varepsilon_{50+n}^{*}\right)$. The larger effects of material benefits due to the higher social multiplier at $\varepsilon_{50-n}^{*}$ compared to $\varepsilon_{50+n}^{*}$ is thus reinforced by a higher density. We can now repeat this comparison for every other twin percentile cutpoints above and below the median. If the cutpoints in the prefectures we observe in the data are continuously distributed along the support of $\varepsilon$, we can conclude that the average effect of material benefits in regions with cutpoints $\varepsilon_{H}^{*}$ below the median must be higher than the average effect in regions with cutpoints above the median.

Of course, we do not observe the cutpoints $\varepsilon_{H}^{*}$ in different prefectures directly, only the shares of Ham-minority households who get minority children $G\left(\varepsilon_{H}^{*}\right)$. However, in the model the cutpoints and shares are one-to-one. Based on the argument above, we can therefore state:

P1 For peer groups who face the same increase in benefits within a province, we should see a larger effect among Han-minority families in peer groups with a share of children with the mother's minority ethnicity below a cutoff, close to the median share, compared to peer groups above that cutoff.

In the data, we will evaluate prediction $\mathrm{P} 1$ by difference in differences, comparing prefectures and cohorts above and below a cutoff share, near the median, of children with the mother's ethnicity, before and after the shift in policy.

Comparing initial cutpoints in different quartiles Prediction P1 relies on a comparison of the effects triggered by changing benefits above and below a cutoff share. Our discussion about the combined effect of a decreasing social multiplier and the density of a single-peaked distribution suggests that we cannot state P1 as a linear interaction between the initial share and the change in benefits. When the initial share of minority kids is in the left part of the distribution, an upward shift in $\varepsilon^{*}$ has an ambiguous local effect due to countervailing effects of

\footnotetext{
${ }^{7}$ This assumption can be weakened to say that the distribution of $\varepsilon$ does not have too much negative skew.
} 
a higher density and a lower social multiplier, whereas the effect gets unambiguous for initial shares on the other side of the median.

We now illustrate this ambiguity and derive an alternative form of our main prediction. To do so, we consider the comparative statics at different segments of the share distribution $G\left(\varepsilon^{*}\right)$ observed in the data, corresponding to different quartiles of cutpoints $\varepsilon^{*}$. Let $\varepsilon_{q}^{*}, q=1,2,3,4$ denote cutpoints located at the middle of the quartiles of the $\varepsilon$ distribution. The (weak) positive skew of the distribution implies that $g\left(\varepsilon_{4}^{*}\right) \leq g\left(\varepsilon_{1}^{*}\right)$ and $g\left(\varepsilon_{4}^{*}\right) \leq g\left(\varepsilon_{3}^{*}\right) \leq g\left(\varepsilon_{2}^{*}\right)$. Moreover, under the assumption that $\frac{d^{2} \Delta}{d \varepsilon^{* 2}}>0$, the first derivatives of the social multiplier are monotonically ordered as: $\frac{d \Delta\left(\varepsilon_{1}^{*}\right)}{d \varepsilon^{*}}<\frac{d \Delta\left(\varepsilon_{2}^{*}\right)}{d \varepsilon^{*}}<0<\frac{d \Delta\left(\varepsilon_{3}^{*}\right)}{d \varepsilon^{*}}<\frac{d \Delta\left(\varepsilon_{4}^{*}\right)}{d \varepsilon^{*}}$. Using these facts in (5), we obtain an alternative testable prediction:

P1' Suppose all peer groups in a province experience the same increase in benefits, due to a provincial policy. Then, the effect on the probability of Han-minority couples having minority children is ( $i$ ) larger in the first, second and third quartile than in the fourth quartile of the share distribution, (ii) larger in the second than in the third quartile, (iii) ambiguous when we compare the first and second quartiles, or the first and third quartiles.

The third part of P1' shows why we cannot use a simple interaction between the initial share and a policy indicator to test the theory. A cutoff in the first quartile is associated with a lower density but a higher social multiplier than a cutoff in the second quartile, and a higher social multiplier but a lower (or higher density) than a cutoff the third quartile. Comparing the effects in the first quartile with those in the second or third quartile thus leads to ambiguous results, which differs from assuming a (weakly) linear impact. We will come back to this difference when discussing our empirical findings.

Auxiliary prediction Our paper focuses on the interaction between individual (material) motives and social motives, as stated in P1 and P1'. An additional testable prediction concerns the interaction effect of material benefits and intrinsic costs. Do the (average) intrinsic costs $e(H)$ of minority children modify the effect of material benefits $b$ for Han-minority couples? Yes, as long as the share of minority children in the peer group is relatively small, material benefits have a smaller effect on the probability of minority children in Han-minority families when intrinsic costs are high. This intuitive prediction may not be specific to our model; other models could also deliver a similar prediction. But a test of it does provide a sanity check on our setup, which we consider in Online Appendix D.

\section{Measurement}

This section discusses how to measure the variables and parameters in the model. We also provide more background information for each variable. Outcomes and some controls are measured 
at the individual level, whereas the individual and social motives are measured at the prefecture, residency, education-group, or ethnicity level.

Linking of data and samples We draw on two sources of data: the 1-percent samples of the 1982, 1990 and 2000 censuses - and the 2005 population survey, also covering about 1 percent of the population. As in the model, we gauge the husband-wife-children structure of households. These can be identified by the head-spouse-child label in the censuses, and by the gender of the head and spouse. We can directly identify children in the 2000 and 2005 data. The 1982 and 1990 censuses do not distinguish between children and children-in-law. To identify children in these earlier data sets, we limit ourselves to unmarried children who still live with their parents. The results we report below are robust to using the 2000 census and the 2005 mini-census only. Below, we also consider composition effects by separating families with one child and multiple children.

Although our data includes three-generation households, we always focus on the head-spousechild structure. Specifically, if a household head lives with his parents and children, we measure the ethnicity of his children (rather than his own ethnicity) ${ }^{8}$ if a head lives with his children and grandchildren, we measure the ethnicity of his children (rather than his grandchildren).

After linking different datasets, our sample of mixed marriages comprises around 235,000 children born between 1970 and 2005. Some 125,000 of these come from Han-minority families and 110,000 from minority-Han families. We start from 1970 because few (13 percent) of the children in the linked data were born before 1970, and we need a representative cohort in the initial period to define the initial shares of children with their mother's ethnicity. ${ }^{9}$

We use administrative units defined by four-digit census codes and always call these prefectures. While all four waves provide information on prefectures, we can only access county-level (six-digit census code) information for 2000. Thus, we focus on prefecture-level norms in our baseline analysis and use county-level information (for 2000) in our supplementary analysis.

Ethnicity outcomes ( $m$ in the model) Censuses always report gender, birth year and ethnicity for each individual, which provides our measure of ethnicity outcomes. However, the data do not report household names, or locations at a finer level than prefectures (or counties). As shown by the summary statistics in Table 1, 47 percent of children in Han-minority families have their mother's ethnicity, whereas only 6 percent do in minority-Han families. This is fact F1 in the introduction. The low shares with mother's ethnicity in minority-Han families is associated with little variation across time, as well as across space. This is consistent with our model predictions discussed in Section 3.2. As a result, we concentrate on children in Han-

\footnotetext{
${ }^{8}$ We make this choice for two reasons. First, the head-spouse-child structure is the most common in the data. Second, we cannot tell parents from parents-in-law, which makes it difficult to examine the ethnicity of household heads.

${ }^{9}$ Including those born before 1970 does not alter the main results.
} 
minority families.

In our analysis to follow, we treat mixed marriages as given. It is possible that some regions are more open to mixed marriages, as well as to minority ethnicities for children. To take this into consideration, we always control for prefecture fixed effects and non-parametric provincial trends (province-by-year fixed effects) in our econometric specifications. In Section 6, we also discuss whether endogenous mixed marriages could explain our main results, and present empirical estimates suggesting they cannot.

Material benefits ( $b$ in the model) Since ethnic material benefits for minority children arise from a bundle of provincial regulations (recall Section 2), it is not straightforward to quantify the regional variation over time. To check that our results are robust, we therefore use three different measures. As mentioned above, these ethnic policies vary at the province level by law, which does not rule out variation at more local levels (e.g., across prefectures) due to different implementation of the same law. However, since we ask how ex ante ethnic policies shape people's choices, it is reasonable to use legislated provincial-level policies.

1. Rollout of the one-child policy. Family-planning policies favored minorities already in the 1960s. But these policies became more generous and more salient in the 1980s, with the switch to a stricter one-child policy. However, minorities enjoy family-planning flexibility. By giving them minority status, parents can thus create an option for their children to have a second child.

To measure its rollout, we employ the timing for 27 provinces used in Edlund et al. (2013). ${ }^{10}$ As explained in that paper and earlier work on family planning (e.g., Peng 1996), the one-child policy is an umbrella for a raft of policies. Edlund et al. (2013) consider three programs: (i) family-planning science and technology-research institutes, (ii) family-planning education centers, and (iii) family-planning associations. Since all these programs make the one-child policy salient, we treat the first year any of them was present in a province by law as the first year of one-child policy. These starting dates range from 1976 (in Jiangsu) to 1984 (in Guangxi).

This measure has the advantage of being staggered across provinces, but the disadvantage of a binary classification that cannot distinguish potentially different material benefits across provinces. ${ }^{11}$

Nothing suggests that the rollout of family-planning institutions is related to ethnic choices of children in mixed marriages. In the data, the $p$-value is 0.759 for the correlation between the year of adopting the instructions and the 1970-74 cohort share of minority children in Han-minority families. We also check empirically for pre-trends.

2. Extra Fertility of Minorities. To capture the intensity of the family-planning policy and its variation over provinces and time, we calculate a second measure, namely the extra

\footnotetext{
${ }^{10}$ Beijing, Shanghai, Tianjin and Chongqing are not included. We thank Lena Edlund for providing this data.

${ }^{11}$ A related measure of the one-child policy is the fines for extra children used in Ebenstein (2010). Because policy rollout is the major driver, our results are robust to using these fines as an alternative measure.
} 
fertility for minorities (relative to Han) after the policy rollout. This measure is allowed to differ by province and by 5-year mother-birth cohort. Specifically, we gauge (close to) completed fertility based on the number of children to Han and minority women aged 40 and above. After the policy, on average, minority mothers have 0.11 more children than Han mothers.

Moreover, the extra fertility measure varies widely across provinces. Panel (a) in Online Appendix B1 presents a map of the ratio of the completed fertilities for minority and Han mothers born in 1955-59 (as of 1995-99). As shown, this ratio is higher in the western provinces.

When matching this measure with the ethnicity-choice data, we use the extra fertility in the previous 5-year cohort of mothers, which is less likely to suffer from endogeneity.

3. Extra Exam Scores of Minorities. To proxy the variation in education benefits for minorities across provinces, we use the extra scores for minorities in the 2000 National College Entrance Exam. ${ }^{12}$ We normalize these extra scores by the cutoff score for four-year universities in a province. ${ }^{13}$ Different from the time-varying measures on fertility, this measure - which ranges from 0 to 6 percent - is only available for the cross section of provinces. In the relevant period, a three-percent extra score is associated with a 2.3 percentage points increase in college admission probability. When matching this measure with the ethnic-choice data, we assume it to be 0 before the introduction of the National College Entrance Exam in 1977, and use the cross-sectional measure for the entire period afterwards.

Panel (b) in Online Appendix B1 presents a map of the extra scores by province. Unlike the extra-fertility scores, the extra-exam scores matter more for southwestern provinces. At the cross-sectional level, the correlation between Measures 2 and 3 is low, with an insignificant correlational coefficient of 0.06 . Thus, the two measures can be considered as two independent policy experiments to examine the responses of mixed-marriage couples. Therefore, we examine the two separately rather than aggregating them into an index.

In sum, the one-child policy has a staggered introduction across provinces, but assumes that (once introduced) the material benefits to minorities are the same across provinces. The extracollege scores instead has cross-sectional variation after its (simultaneous) introduction, while the extra-fertility score has cross-sectional as well as time-series variation. We use all three measures of material benefits in our analysis. The number of observations varies slightly due to data availability.

Peer groups for social motives (related to $\frac{d \Delta}{d \varepsilon^{*}}$ in the model) Following the discussion about crowding in or crowding out in Section 3 (the sign of $\frac{d \Delta}{d \varepsilon^{*}}$ ), we measure social motives by the shares of children with mother's ethnicity in mixed marriages. To avoid the reflection

\footnotetext{
${ }^{12}$ We cannot access the data for a long period, but at least during 1999-2003, we find the extra scores for minorities very stable.

${ }^{13}$ There are separate cutoffs for first-tier and second-tier universities in a province. We normalize the extra scores by the second-tier cutoff. The results are robust to using the first-tier cutoff (since the two cutoffs are highly correlated).
} 
problem discovered and discussed by Manski (1993), we want to treat the social motives for a particular cohort as predetermined by previous choices in the peer group.

Because we cannot observe the relevant peer group directly and our data reflect a population sample, we define the peer group relevant for the social motives in different ways in the hope of avoiding biased estimates. In line with the model, where people are influenced by others who make the same decisions, we use a choice-based definition of peer groups. In particular, we associate each Han-minority couple with a set of couples in a certain location who have the opportunity to choose the same ethnicities for their children. ${ }^{14}$ In addition, we also allow for a wider peer group by considering all families who can choose to follow the mother's ethnicity or not.

1. The 1970-74 cohort from Han-minority families in the same prefecture. We exploit the variation across prefectures in the 1970-74 birth cohort - i.e., in the initial cohort unambiguously before the start of the dramatic changes in ethnic policies. This treats the social motives as predetermined over the period of changing policies (and also allows us to examine the dynamic impacts of social motives over time).

2. The 1970-74 cohort in the same prefecture from Han-minority families, subdivided by residence, education, or wife's ethnicity. The measure in $\mathbf{1}$. only uses the husband's ethnicity, the wife's minority status, and prefecture to define the peer group. But we also consider a number of finer peer groups. A. The first group conditions also on urban or rural residence and defines the peer group at the prefecture-ethnicity-cohort-residency level. Specifically, we distinguish between urban and rural based on the husband's Hukou (legal residence). Definition 2.A implies smaller groups in each cell than definition 1., by disaggregation and by the fact that we rely on rural/urban information in the 2000 and 2005 censuses. ${ }^{15}$ B. One may argue that peer groups are plausibly formed by people with similar levels of education. Our second refinement thus conditions on father's education. Specifically, we distinguish those who have completed high-school or above. This way, we define the peer group at the prefectureethnicity-cohort-education level. Since material benefits (especially education benefits) can differ by education groups, this definition also helps us check the heterogeneity by education levels. C. Yet another possibility is that the relevant peer group for a Han man and minority woman is limited to other couples, where the wife has the same minority ethnicity. We consider this possibility as well, by defining the peer group at the prefecture-cohort-(female)ethnicity level.

3. The 1970-74 cohort from Han-minority families in the same county. Instead of prefectures, we also use a narrower definition. But we can only access the county information

\footnotetext{
${ }^{14}$ The prospective econometric problems of estimating the influence of unobserved peer groups in a sample from the population appear related to the biases due to measurement error when estimating peer effects for members of partially sampled networks (Chandrasekhar and Ellis, 2011).

${ }^{15}$ Rural/urban information was asked in the 1990 but not in the 1982 census, which makes it absent from the merged 1982-90 data by IPUMS. It is possible to identify it based on separate information for 1990 . We choose not to do so to keep consistency with the IPUMS merged data. This also serves as a check on whether our findings hold with the 2000 and 2005 censuses only.
} 
for 2000 .

4. All mixed couples in the 1970-74 cohort in the same prefecture able to make an ethnic choice All peer group definitions under 2. are refinements of definition 1. To check for robustness, we also consider a broader peer group, namely the share of children with mother's ethnicity, among all couples that can make such a choice (Han-minority couples, minority-Han couples and minority-minority couples with different ethnicities).

Pre-policy variation in share of children with mother's ethnicity $\left(G\left(\varepsilon^{*}\right)\right.$ in the model) As mentioned in Section 2, Figure 2 shows a great deal of variation across prefectures for Hanminority mixed families. In terms of the model, this dispersion reflects the joint distribution of parameters $b, e(H), \mu$ leading to different cutoffs $\varepsilon^{*}$ and the mapping from these cutoffs into shares via distribution $G$. In contrast, for minority-Han mixed families, most prefectures are concentrated at the left end, leaving little variation across prefectures. As stated before, we therefore focus on the social motives for Han-minority families. In addition, the pattern for the Han-minority families in Figure 2 suggests that the likelihood for sons to get their mother's ethnicity is lower than that for daughters, which is consistent with the interpretation that the intrinsic identity costs for parents are higher for sons in this patriarchal society.

Figure 4 maps the spatial distribution across China of ethnicity choices by Han-minority couples (in the 1970-74 cohort). It suggests that the social motives vary considerably across prefectures, and that this variation is not strongly geographically clustered. For instance, province fixed effects only explain about a third of the variation across prefectures.

For Han-minority families, our model predicts a strategic complementarity $\frac{d \Delta}{d \varepsilon^{*}}<0$ for low values of cutoff $\varepsilon^{*}$ (low norm-breaking shares) and a strategic substitutability $\frac{d \Delta}{d \varepsilon^{*}}>0$ for high values of $\varepsilon^{*}$ (high norm-breaking shares). If the distribution of $\varepsilon$ were symmetric, the sign would flip at a critical cutoff of $\varepsilon_{50}^{*}=0$, corresponding to a share of minority kids at 0.5 . But we would like to allow for a non-symmetric distribution.

Empirically, we do this in two ways. First, we check how the estimates behave as we vary the assumption about the critical cutoff in the neighborhood of 0.5, when testing Prediction P1. Second, we look at the estimates in different quartiles, when testing Prediction P1'.

Other prefecture and individual characteristics We control for a set of prefecture and individual variables. At the prefecture level, we include characteristics that might affect ethnic choices: whether a prefecture is a borderland, its minority population share in the 1982 census, its population share with high-school education or higher in the 1982 census, as well as the number of children for minority women (aged 40 and above) in the 1982 census. The direct level effect of these characteristics are absorbed by prefecture fixed effects. To rule out that the identifying variation in the (pre-policy) share of children with their mother's ethnicity is systematically related to the change in ethnic policies, we allow the prefecture controls to have 
different impacts before and after the introduction of the ethnic policies (interacting them with our measures of ethnic benefits).

We present correlations between these characteristics and our baseline measure of social motives (pre-policy share of minority children in Han-minority families) in Online Appendix B2. It is worthwhile pointing out that correlation between our measure of social motives and the share of minority population is weakly positive. This correlation rejects a "scarcity" effect, whereby children are less likely to be minority in regions with a higher minority population share because a more or less fixed set of material benefits gets diluted by many takers.

At the individual level, we include education-level fixed effects and 5-year birth-cohort fixed effects for both father and mother. We unify the categorical education levels across censuses into four groups: $1=$ less than completed primary school, $2=$ completed primary school, $3=$ completed secondary (high) school, and $4=$ some college education or more. As Table 1 shows, the average husband has more education than the average wife. To rule out that our estimated effects are driven by omitted individual variables, we allow the impacts of these individual characteristics on ethnic choices to differ before and after any policy shifts.

Migration The variation across prefectures and provinces discussed in this section is based on residency at census time. However, migration may make residency different than birth place. Only the 2000 census includes information on whether an individual's birth place and current residency coincide (the 1982 and 1990 censuses spell out if people lived in the same county five years ago, while the 2005 mini-census only has that information one year ago). Based on the 2000 census, over 85 percent of individuals were born in the same county as their current residence, while 94 percent were born in the same province. Given that prefecture is the administrative level in between county and province, these facts suggest that migration is unlikely to make a major difference for our main results. Moreover, Frijters, Gregory and Meng (2013) document that rural-urban migration did not take off until 1997. Nevertheless, we conduct robustness checks by omitting the (most recent) 2005 census from the sample, and by excluding individuals whose birth and residence counties are different. This should minimize the potential impact of migration. In addition, we show that the interaction of material benefits and social motives (our main effect) has no impact on migration outcomes in the 2000 census.

\section{Empirical Evidence}

The most important new prediction(s) from our model is P1 (and P1') on the interactions between individual and social motives. To the best of our knowledge, no similar prediction has been studied in the existing literature. This section confronts that prediction with data. 


\subsection{Testing P1 and P1'}

Our model of the interactions between individual and social motives predicts a larger effect of higher material benefits in peer groups where the initial share of children breaking the social norm (with the mother's ethnicity) is smaller. This is because individual motives driven by material benefits are crowded in rather than crowded out by prevailing social motives. Empirically, Prediction P1 relies on a comparison of the effects above and below a cutoff share.

Main specification To test Prediction P1, we ask whether $\beta_{b}$ is positive in the difference-indifferences specification:

$$
\begin{aligned}
C M E_{i, p, t}= & \beta_{b} I(\leq V)_{p} \times b_{r, t}+b_{r, t}+\text { birthyear }_{t}+\text { pref }_{p} \\
& + \text { ethn }_{g}+\gamma \mathbf{X}_{i, p}+\gamma^{\prime} \mathbf{X}_{i, p} \times b_{r, t}+\text { prov }_{r} \times \text { year }_{t}+\varepsilon_{i, p, t},
\end{aligned}
$$

where the dependent variable $C M E_{i, p, t}$ is a binary indicator for child $i$ - with Han father and minority mother of ethnic group $g$, in prefecture $p$ (belonging to province $r$ ), and birth year $t-$ having the mother's ethnicity.

The material benefits from ethnic policy $b_{r, t}$ are measured in the three ways discussed in Section 4. Thus $b_{r, t}$ (Post Policy) is a dummy for whether province $r$ has implemented the one-child policy, $b_{r, t}$ (Extra Fertility) is the extra fertility for minorities in the province post the one-child policy, and $b_{r, t}$ (Extra Scores) is the extra score for minorities in the provincial national college-entrance exam.

$I(\leq V)_{p}$ is an indicator for whether the peer group - by Definition 1 in Section 4, i.e., Han-minority couples with children in the 1970-74 birth cohort in the same prefecture has a minority-children share below some critical value $V$ between 0 and 1 . This value corresponds to the theoretical borderline between crowding in and crowding out. Thus, the parameter of interest $\beta_{b}$ measures the interaction between material benefits and social reputations: the difference in the effect of material benefits in prefectures below and above the cutoff.

To allow time-invariant, or slowly changing, prefecture characteristics - like attitudes to mixed marriages - to influence ethnicity choices, we include prefecture fixed effects $\left(\right.$ pref $\left._{p}\right)$. To hold constant factors that affect China-wide ethnicity choices by different cohorts (like the average effects of post-policy material benefits), we include birth-year fixed effects (birthyear ${ }_{t}$ ). To control for time-invariant or slowly changing ethnicity-specific factors, we include (a set of 55) ethnicity fixed effects $\left(e t h n_{g}\right)$. For example, some minority groups may have stronger preference that the child maintains the father's ethnicity. As we focus on the children of Han-minority couples, these fixed effects refer to the wife's particular minority ethnicity.

$\mathbf{X}_{i, p}$ is the set of individual and prefecture characteristics presented in Section 4 and we include $\mathbf{X}_{i, p} \times b_{r, t}$ to allow their impacts on individual behavior to change with material benefits.

Finally, we include province-by-calendar-year non-parametric trends $\left(\operatorname{prov}_{r} \times\right.$ year $\left._{t}\right)$ to con- 
trol for different evolutions across provinces, such as the direct effects of different provincial policies, or different evolutions of discrimination against minorities. We cluster the standard errors at the prefecture level and present those clustered at the province level as a robustness check.

Baseline results We start with a cutoff share $V=0.5$ and $b_{r, t}$ (Post Policy) as the material benefits in Table 2A. Columns (1)-(2) of the table only include prefecture fixed effects. Column (1) shows that the average effect of $b_{r, t}$ (Post Policy) is around 0.078 - i.e., an additional 7.8 percentage points of Han-Minority couples choose to have a minority child after the introduction of the one-child policy, which is around $19 \%$ of the pre-policy mean (41 percentage points). Column (2) presents the interaction effect of interest, on $I(\leq 0.5)_{p} \times b_{r, t}$ (Post Policy), which shows that effect of material incentives is indeed significantly larger when the share of children following mother's ethnicity is smaller than 0.5. The estimated interaction effect is quantitatively large, at least on the order of the average effect in column (1). This is consistent with Prediction P1 that benefits have a larger effect in peer groups where few mixed households break the social norm by giving their children the mother's ethnicity, as this leads to a strategic complementarity (and a social multiplier above 1) rather than a strategic substitutability (and a social multiplier below 1). For example, given the estimates in column (2), the average effect of the introduction of the one-child policy is around 10 percentage points below the 0.5 cutoff and 3 percentage points above the cutoff. ${ }^{16}$

Column (3) adds wife-ethnicity fixed effects. Column (4) further includes birth-year fixed effects - as $82 \%$ of the variation in the policy measure is absorbed by these birth-year fixed effects, the coefficient on $b_{r, t}$ (Post Policy) is omitted from the results (but still appears in the regression). These columns both display an estimate of $\beta_{b}$ similar to that in column (2). Column (5) shows that the column (2) results are little affected by including prefecture and individual characteristics and their interactions with $b_{r, t}$ (Post Policy). Column (6) further shows that the pattern is robust to non-parametric provincial trends (province-by-calendar-year fixed effects).

The standard errors in parentheses are clustered at the prefecture level and those in brackets are clustered at the province level. The estimate of $\beta_{b}$ is significantly different from zero, regardless of the levels of clustering. As this is also true for all results to follow, we only show the results for prefecture-level clustering in subsequent tables.

Alternative policy measures In Table $2 \mathrm{~B}$, we employ two additional measures of material benefits, $b_{r, t}\left(\right.$ Extra Fertility) and $b_{r, t}$ (Extra Scores). We limit ourselves to three specifications for each policy measure, namely those in columns (2), (4) and (6) of Table 2A. To facilitate the comparison, we present the impacts of a one-standard-deviation $(1 \sigma)$ increase of the measures.

\footnotetext{
${ }^{16}$ Instead of examining an interaction effect, one can also evaluate the effect of Post $_{r, t}$ in separate samples with prefectures below and above the cutoff (the difference between the specifications is from which samples the fixed effects are estimated). The results are very similar.
} 
As shown in column (1), a $1 \sigma$ extra fertility is associated with a 3.4 percentage point increase in the probability of having a child with mother's ethnicity. By columns (2)-(3), the difference in impact below and above the cutoff is on the order of the average effect. Columns (5)-(6) present the results for $b_{r, t}$ (Extra Scores), which exhibit a similar pattern as extra fertility. Column (7) presents a specification which includes both these policy measures, and shows that their impacts are comparable. As mentioned in Section 4, the variation in the two measures are only weakly correlated, so they can be considered as largely independent interventions.

Alternative cutoffs We further examine the impacts of $b$ for different cutoffs. For the same specification as column (6) of Table $2 \mathrm{~A}$, we visualize the corresponding interaction estimates and their 95 percent confidence intervals for all cutoffs $V$ between 0.1 and 0.9 (see Online Appendix C1). Each estimate represents the different effects of $b_{r, t}$ on individuals in prefectures below and above cutoff $V$. For $b_{r, t}$ (Post Policy) and $b_{r, t}$ (Extra Fertility), the positive impact is significant for all cutoff values from 0.3 and upwards; for $b_{r, t}$ (Extra Scores), it is significant for all cutoff values from 0.4 and upwards. As discussed next, a lower point estimate at the lowest cutoffs is consistent with the model.

Quartile results (P1') In Section 3, Prediction P1' stated the predicted effects of interacting individual and social motives in different quartiles. To consider this prediction, we replace $I(\leq$ $0.5)_{p}$ in (9) with three indicators for the early 1970s cohort share of minority children being in the quartiles: $I(0-0.25)_{p}, I(0.25-0.50)_{p}$, and $I(0.50-0.75)_{p}$. We thus leave the fourth quartile as the reference group.

Prediction P1' is confirmed by the results in Table 3, again for the peer group of all HanMinority couples in the same prefecture with children in the 1970-74 cohort. Columns (1)-(3) present the estimates when the three quartile indicators are interacted with $b_{r, t}$ (Post Policy): column (1) includes only prefecture fixed effects; column (2) adds ethnic fixed effects (for the minority wife) and birth-year fixed effects; column (3) further adds the interaction effects of prefecture and individual characteristics and province-by-calendar-year fixed effects. Columns (4)-(9) present analogous results using $b_{r, t}$ (Extra Fertility) and $b_{r, t}$ (Extra Scores) to measure material benefits. Consistent with Prediction P1', the effect of material benefits is significantly larger in the first, second and third quartile compared to the fourth quartile. Also consistent with the prediction, the point estimates for the second quartile are indeed significantly higher than that for the third quartile (a $p$-value smaller than 0.05 in all specifications).

As in the test of Prediction P1, these effects are large: the difference in effects of higher material benefits, say, in the first vs. the fourth quartile is on the order of the average effect estimated in Table 2. This corresponds to the theoretical prediction of a social multiplier above 1 in the first quartile - due to crowding in - and a social multiplier below 1 in the fourth quartile - due to crowding out. Another indication of a substantial variation in the social multiplier is that the empirically estimated effect in the first quartile is everywhere larger than that in the 
third quartile. As stated in Prediction P1', this relative effect is theoretically ambiguous, as the social multiplier is higher but the density is lower when we compare the first with the third quartile. ${ }^{17}$ Empirically, we find a smaller difference between the first and third quartiles than between the second and third quartiles, which further supports the theoretical prediction of a non-linear effect. ${ }^{18}$

\subsection{Robustness}

This subsection checks if our baseline results are robust to potential mis-measurement due to migration, pre-trends before the policy shift, and endogenous mixed marriages.

Migration To deal with mis-measurement due to migration, we re-estimate the baseline results, dropping all post 2000 data as well as individuals whose birth and residency counties are different in the 2000 census. The results, presented in columns (1)-(6) in the table of Online Appendix C2, entail estimates similar to those in Table 2. Columns (7)-(9) of the same table show that $I(\leq 0.5)_{p} \times b_{r, t}$ has no significant impact on being a migrant in the 2000 census. These results suggest that our main finding is unlikely to be driven by migration per se.

Dynamic impacts and pre-trends Our baseline specification highlights the average effect of material benefits. A more flexible way of examining the impact of $b_{r, t}$ (Post Policy) is to allow the effect to vary by birth cohort:

$$
\begin{aligned}
C M E_{i, p, t}= & \sum_{\tau=-3}^{\tau=+3} \beta_{b, \tau} \text { Cohort }_{r, \tau} \times I(\leq 0.5)_{p}+\sum_{\tau=-3}^{\tau=+3} \text { Cohort }_{r, \tau}+\text { birthyear }_{t}+\text { pref }_{p} \\
& + \text { ethn }_{g}+\gamma \mathbf{X}_{i, p}+\gamma^{\prime} \mathbf{X}_{i, p} \times \text { Post }_{r, t}+\text { prov }_{r} \times \text { year }_{t}+\varepsilon_{i, p, t} .
\end{aligned}
$$

Here, the birth cohort 1-3 years before the family-planning policy (i.e., $\tau=-1$ ) is the reference group and $\tau \in\{-3,-2,0,1,2,3\}$ refers to 7 or more years before the policy, 4- 6 years before the policy, 0-2 years after the policy, 3-5 years after the policy, and 6 or more years after the policy.

If the estimates of $\beta_{b,-3}$ and $\beta_{b,-2}$ are different from zero, prefectures with different social motives were different already before the introduction of ethnic policies. In effect, $\beta_{b,-3}$ and $\beta_{b,-2}$ are weakly negative and insignificant, indicating that pre-trends are not critical. The estimation results are presented in Online Appendix C3 and visualized in Figure 5 (where the bars indicate 95\% confidence intervals when standard errors are clustered at the prefecture level).

The interaction between individual and social motives becomes significantly positive after the policy shift. Moreover, the size of this interaction effect is increasing over time. These

\footnotetext{
${ }^{17}$ Also, Figure 2 suggests that the empirical density of the equilibrium prefectural cutoffs is skewed with a relatively high density in the first quartile,

${ }^{18}$ This finding rejects an alternative hypothesis: the effect is (weakly) decreasing in the share measure. Because the effect is larger in the second quartile than that in the third quartile, the alternative hypothesis would predict an even larger difference between the first and the third quartiles.
} 
results are consistent with a dynamic extension of the model presented in Online Appendix C4. Specifically, if the social motives of each cohort are tied to the behavior of the previous cohort, equation (3) still defines a steady state value for $\varepsilon_{H}^{*}$. However, the equilibrium adjusts towards the new steady state according to the non-linear difference equation:

$$
b-e(H)-\varepsilon_{H, t}^{*}=\mu \Delta\left(\varepsilon_{H, t-1}^{*}\right) .
$$

In this dynamic setting, the dynamic adjustment - impulse response - to the same $b$ shock predicts that the difference between peer groups with low and high initial shares should go up over time, as it does in the data.

Outliers While our results exploit within-province and within-ethnicity variation, one may still wonder if they are driven by outlier provinces or ethnicities. All the baseline results (as well as all other results to follow) are robust to outliers, in that they hold up to dropping one province, or one ethnic group, at a time.

Endogenous mixed marriages An important concern about our analysis is that Hanminority marriages may be simultaneous with the ethnic choice of children. If unobserved factors drive the incidence of mixed marriages as well as the ethnicity choices in such marriages, our findings in Tables 2 may just proxy for those omitted drivers rather than capture an interaction between individual and social motives. An increase in Han-minority mixed couples can only explain a higher share of children with their mother's ethnicity, however, if the additional mixed couples are more likely to break the social norm. Our analysis provides a specific answer as to why couples married after the ethnic policies do so. But in a broader context, mixed marriages are certainly endogenous. In fact, we are currently doing additional research on the incidence of mixed marriages. While we leave the question about the drivers of mixed marriages for an accompanying paper, it is important to examine whether these marriages can explain our main findings.

The sharpest way to deal with this issue would be to examine choices within the same family, before and after the implementation of ethnic policies. At the aggregate level, the share of mixed couples (with more than one child) with children of different ethnicities goes up from $3.6 \%$ to $4.5 \%$ after the implementation of the one-child policy. To conduct an individual-level withinfamily analysis, however, we must limit the sample to Han-minority families with some children born before and some children born after the policy. Since this restriction preserves only $9 \%$ of the mixed couples in our sample, we do not have enough power for a within-family analysis at the prefecture level - family fixed effects explain over $97 \%$ of the variation in children's ethnicity.

A less satisfactory approach which still provides a useful check, is to consider the subsample of couples who were married before the introduction of ethnic policies as the marriage decision of these couples is very unlikely affected by the ethnic policies. The restriction to early marriages, 
plus the fact that marriage-year information is available only in the 2000 and 2005 censuses, considerably cuts the sample from that in our baseline estimates.

Estimation results for this smaller sample are presented in columns (1)-(6) of Table 4, for our three measures of material benefits. Since we exclude all couples married after the policy, most children in the sample were born before 1985. The resulting post-policy period is thus very short, which explains why the average effects of higher material benefits in columns (1), (3) and (5) are smaller than in the full sample - recall the dynamic pattern in Figure 5. However, the interaction effects with the social motive in columns (2), (4) and (6) are positive and similar in magnitude to the average effect, precisely as our baseline estimates in Table 2A. The magnitude of $b_{r, t}$ (Post Policy) is also similar to the results in Online Appendix C3 for the interaction effect 1-3 years after the policy.

Another way to deal with the concern of endogenous mixed marriages is to re-estimate our baseline specification in Table 2 , but add the mixed-marriage share and its interaction with the share indicator $I(\leq 0.5)_{p}$ in the same prefecture. Columns (7)-(9) of Table 4 show that this only very marginally alters the estimates of the central interaction effects in Table 2.

The bottom line is thus that our baseline pattern on the interactions between individual and social motives appears to hold up in the wake of endogenous mixed marriages.

\subsection{Alternative Peer Groups}

Peer groups play a key role in our model. The empirical estimates we have shown so far rely on the assumption that an earlier cohort of Han-minority couples in the same prefecture makes up the relevant peer group for ethnicity decisions. As peer groups are not observable, it is important to consider alternatives. In particular, our definition may be too wide if a certain Han-minority couple is more influenced by other such couples who live under similar conditions, have the same education, or a wife from exactly the same minority ethnicity. Below, we consider these three possibilities.

One may also argue that our definition is too narrow. Would Han-minority couples be also influenced by minority-Han and minority-minority couples who can choose to break the norm? We also consider this possibility.

Narrower peer groups Panel (a) of Table 5 presents separate results for rural-resident and urban-resident members of the same ethnicity-prefecture-cohort (peer-group definition $2 \mathrm{~A}$ in Section 4). Although based on a considerably smaller sample, the estimates of the interaction between individual and social motives deliver a similar message as the prefecture-cohort-level results in Table 2. The effects are generally larger for urban residents, consistent with the fact that family-planning policies are more strictly enforced in cities. These results also show that our main finding in Table 2 is unlikely to be driven by different perceived values of ethnic benefits ( $b$ in the model). Another possibility is that rural and urban residents put different weight 
people on social reputations ( $\mu$ in the model). We do not attempt to empirically disentangle the impacts of $\mu$ and $b$.

Another narrower peer-group definition subdivides each mixed-couples cohort by educational background. In particular, we split the sample (according to definition 2B) into those with less than a high-school education, and those with high-school or more. The results are presented in panel (b) of Table 5. On average, families with more education are more likely to break the norm and choose minority for their children. Multiple channels can account for this difference: the better educated may have better information, perceived higher benefits of education, or attach less importance to tradition. Our focus, however, is still on the interplay between material motives and social motives. As shown, the estimated interaction effect between individual material motives and social motives appears comparable for these two groups.

The estimates presented so far assume that all mixed couples with a Han man and a minority wife - no matter which minority - belong to the relevant peer group. What if we restrict the peer group to each specific minority group of the wife (definition $2 \mathrm{C}$ )? To check this, we allow each cohort in a prefecture to make up 55 different peer groups. In practice, the average number is much smaller due to the regional dispersion of minorities. The central estimates, presented in panel (c) of Table 5, are slightly larger than the baseline estimates in Table 2.

In addition, we use the county information (available in census 2000) to define peers. Once again, we find a similar pattern (presented in panel (d)). If anything, the coefficients are larger than in our baseline. Altogether, the results in panels (a)-(d) show that our results are robust to narrower peer groups.

A wider peer group Opposite to the refinement in panels (a)-(d) of Table 5, panel (e) presents results for a wider peer group: all Han-minority, minority-Han, and minority-minority couples that can choose whether to break the norm. Using the same specification as in panels (a)-(c), panel (d) shows a similar pattern for this wider peer group. The findings in Table 5 show that our main result is unlikely to be driven by the specific peer-group definition in our baseline specification.

In summary, the results reported in Section 5.1-5.3 constitute solid and robust evidence that peer-group dependent social motives help shape the effect of individual material benefits on individual ethnicity choices. As in the theory, stronger material motives are either crowded in or crowded out social motives, depending on the initial equilibrium in the peer group. The interaction between individual and social motives appears to be not only statistically significant but also quantitatively significant.

As mentioned in Section 3, our model also predicts that when intrinsic costs are high, material benefits have a smaller effect on the probability of minority children in Han-minority families. In Online Appendix D, we present supportive evidence for this sanity check, when intrinsic costs are proxied by male gender of the child and religiosity of the wife's ethnicity. 


\section{$6 \quad$ Alternative Explanations}

Our model is consistent with motivating facts F1-F2 in Chinese micro data. Its central predictions P1 and P1' are also borne out by the data. Our model is thus a plausible framework to understand the interaction of individual and social motives for identity choice. But could our findings be explained by other theoretical and empirical mechanisms? In this section, we discuss two alternative ways of specifying the model and four alternative ways of interpreting the empirical findings. The bottom line of this discussion will be that even though some of the alternative explanations may indeed help us think about the data, they are unlikely to drive our main results on individual-social interactions. Other alternatives can be ruled out a priori, on either theoretical or empirical grounds. We summarize the key conceptual issues for each explanation and present the detailed modeling and estimations in Online Appendix E.

Nonlinear utility In our version of the Benabou-Tirole model, couples have preferences, which are linear in material benefits $b$ and intrinsic costs $e+\varepsilon$, but nonlinear in social reputations $\mu E(\varepsilon \mid m)$. What if we got rid of the social-reputation term, but made preferences concave in individual benefits and context in intrinsic costs. Could this reproduce the prediction that higher benefits would have a larger effect on the share of children breaking the social norm (by adopting the mother's ethnicity) when the share is smaller? As we show in Online Appendix $\mathrm{E} 1$, the answer is no. Intuitively, due to the convexity of the cost function, the effect of $b$ is smaller at lower values of $\varepsilon^{*}$ (lower norm-breaking shares), which contradicts Prediction P1.

Social interactions How particular are our theoretical predictions and empirical results to the assumed form of social interactions? The latter has two dimensions: how the social motive enters the household's preferences, and which social peer group is the relevant one for the household. We have examined alternative peer groups in Section 5. In this subsection, we discuss the specific functional-form assumption and show that the most natural alternatives cannot explain our findings.

As we have stressed, our version of the Benabou-Tirole model produces either crowding in or crowding out, because people take into account not only the stigma of breaking the social norm but also the honor of obeying it, given how others in their peer group behave. Many papers in the literature consider only the stigma of breaking the norm, and assuming that it becomes smaller if more people do so. But this is equivalent to assuming strategic complementarity, and hence crowding in a priori.

How important is the model's form for social reputation, namely that people choose identity for their children to signal their expected type, given how everybody else in the peer group behaves? One could think of other ways of modelling social reputation. The most natural alternative is to assume that the honor of a child with father's ethnicity and the stigma of a child with mother's ethnicity are given by the shares of norm-followers and norm-breakers 
in the peer group. As derived in Online Appendix E2, such an assumption would typically lead to strategic complements only. The attractiveness of our social-reputation model defined over expected types is that it delivers non-trivial and testable predictions about the interaction between individual and social motives without overly strong functional-form assumptions.

Bargaining power Bargaining between husbands and wives, with conflicting preferences, is an alternative mechanism behind some of the patterns in the data. Consider facts F1 and F2 in Figure 1. Assume that women's bargaining power have gone up over time so that a higher number of Han-minority couples chose the mother's minority ethnicity for their children. One may further argue that this mechanism may have become more powerful post ethnic policies, due to social and economic factors, like unbalanced and increasing sex ratios - more men per woman - among the Han. However, a bargaining mechanism cannot explain our main finding on Prediction P1, neither in the theory nor in the data. In Online Appendix E3, we first sketch a bargaining model. Intuitively, to explain P1, one has to make the very specific assumption that bargaining power has risen over time and more so in peer groups with lower shares of minority children.

Empirically, we can proxy bargaining power by three measures: education differences, or age differences, between husband and wife, as well as sex ratios of children. In all cases, we find no evidence that bargaining power rises more in peer groups with lower shares of minority children. Moreover, our main results are robust to considering these measures and their interactions with the cutoff indicator in Tables 2A-2B. These estimation results are presented and discussed in Online Appendix E3.

Minority population share Our findings on Prediction P1 cannot really be explained by variation in the share of minorities in the prefecture population. First, this prediction is about the share of minority children in Han-minority families rather than the share of minorities itself. As discussed in the prefecture-level correlations, however, these two measures are weakly positively correlated. This suggests that our findings are unlikely to be driven by a "scarcity" effect, whereby children are less likely to be minority in some regions because a more or less fixed set of material benefits get diluted by a larger minority population. Such scarcity is also unlikely a priori, as ethnic policies are not set by fixed quotas.

One may also argue that a higher minority population share works in the same direction as the share of minority children in Han-minority families. In particular, if the minority population share in a prefecture is small, ethnic conflict is less likely to be a social problem and parents may feel safer to break the norm and choose minority for their children. Tables 2A-2B already show that our findings hold conditional on the minority-population share and its interaction with the ethnic policies $b_{r, t}$. Moreover, the coefficients on this interaction term are not significant in those specifications (with a $p$-value of 0.46 in column (6) of Table $2 \mathrm{~A}$ ). Thus, our findings are not affected by the share of minority population and there is no empirical evidence for a scarcity 
or conflict effect.

Censoring Another possible concern is that our main result could be mechanically explained by a kind of upward censoring. Specifically, our finding of a larger policy effect in prefectures with a small minority-children share could reflect that there is little room to respond when this share is large and approaching one. To check for this, we restrict the estimation sample to prefecture-cohorts with a minority-children share between 0.3 and 0.7 . In this interval, there should be enough room for Han-minority couples in every prefecture-cohort to respond without hitting a constraint. As shown in Online Appendix E4, the estimates from the restricted sample are similar to the baseline estimates from the full sample in Table 2A. Upward censoring thus does not drive our main findings. Moreover, the evidence supporting P1' (the effects by quartiles) also suggests that censoring is unlikely to be the main driver. In fact, we find that the effect for the second quartile is typically larger than that for the first quartile.

Composition effects Finally, the results could conceivably capture another mechanical effect. Specifically, some Han-minority couples may always have children with the father's Han ethnicity and others may always have children with the mother's minority ethnicity. Suppose now that after the one-child policy, couples who choose the mother's minority ethnicity have a larger number of children than those who choose the father's Han ethnicity. Such composition effects could explain our results without any change in behavior (other than regarding the number of children).

To check this, in Online Appendix E5 we present separate results for families with a single child (in columns (1)-(3)) and for those with multiple children (in columns (4)-(6)). As these estimates show, the results for both types of households are similar to the baseline findings in Table 2A. If anything, the pattern is slightly stronger for single-child families. Our baseline results on Prediction P1 are thus not driven by composition effects.

\section{Conclusion}

Characterizing the interplay between individual and social motives is relevant in many contexts. In this paper, we provide theoretical and empirical analyses of ethnicity choices for the children in China's interethnic marriages. Drawing on earlier work by Benabou and Tirole (2011), we present a model which is consistent with motivating facts in the data. The model also delivers additional predictions, which are supported by empirical tests on Chinese census data. Most importantly, changes in individual material motives triggered by policy interventions are crowded in (out) by social motives when social-stigma concerns dominate (are dominated by) social-honor concern, precisely in the way that theory predicts.

Our methodology for using micro data to investigate how social reputations modify the effect of individual incentives complements recent studies in experimental settings. One can apply a 
similar approach on observational data to a set of different issues - where both individual and social motives are likely to be important - e.g., in tax evasion, political participation, fertility, or environment-friendly investments.

Our study also adds to the effort of understanding the determinants of identity choice. While scholars have realized that both individual and social motives drive identity decisions, few have formalized the interplay among individual material incentives, individual intrinsic motives, and social reputations. Our study may open avenues for future research on identity choice in other settings.

Finally, we hope that our study makes a contribution specific to China, where the economics and politics of ethnicity have been important issues, yet rarely studied with economic methods. In future work, we hope to extend our empirical analysis to predictions from a model of directed marriage search, asking which individuals end up in mixed couples in the first place. Then, the ethnic choices for children analyzed in this paper would help determine the continuation value from the marriage stage. In addition, the recent abolition of the one-child policy provides another testing ground for our design, which we have to leave for the future work.

\section{References}

[1] Akerlof, George and Rachel Kranton (2000), "Economics and Identity", Quarterly Journal of Economics 115, 715-753.

[2] Atkin, David, Eve Colson-Sihra, and Moses Shayo (2019), "How Do We Choose Our Identity? A Revealed Preference Approach Using Food Consumption", NBER working paper 25693.

[3] Ariely, Dan, Anat Bracha, and Stephan Meier (2009), "Doing Good or Doing Well? Image Motivation and Monetary Incentives in Behaving Prosocially", American Economic Review 99, 544-55.

[4] Bates, Robert (1974), "Ethnic Competition and Modernization in Contemporary Africa", Comparative Political Studies 6, 457-484.

[5] Benabou, Roland and Jean Tirole (2011), "Laws and Norms", NBER Working Paper, No 17579.

[6] Besley, Timothy, Anders Jensen, and Torsten Persson (2018), "Norms, Enforcement and Tax Evasion", mimeo, IIES and LSE.

[7] Bisin, Alberto and Thierry Verdier (2000), "Beyond the Melting Pot: Cultural Transmission, Marriage, and the Evolution of Ethnic and Religious Traits", Quarterly Journal of Economics 115, 955-988. 
[8] Bisin, Alberto, Giorgo Topa, and Thierry Verdier (2001), "Religious Intermarriage and Socialization in the United States", Journal of Political Economy 112, 615-664.

[9] Botticini, Maristella and Zvi Eckstein (2007), "From Farmers to Merchants, Conversions, and Diaspora: Human Capital and Jewish History", Journal of the European Economic Association 5, 885-926.

[10] Bursztyn, Leonardo, and Robert Jensen (2017), "Social Image and Economic Behavior in the Field: Identifying, Understanding, and Shaping Social Pressure", Annual Review of Economics 9, 131-153.

[11] Bursztyn, Leonardo, Michael Callen, Bruno Ferman, Saad Gulzar, Ali Hasanain, and Noam Yuchtman (2014), "Identifying Ideology: Experimental Evidence on Anti-Americanism in Pakistan", NBER working paper 20153.

[12] Cantoni, Davide, David Y. Yang, Noam Yuchtman, and Y. Jane Zhang (2018), "Protests as Strategic Games: Experimental Evidence from Hong Kong's Anti-Authoritarian Movement", Quarterly Journal of Economics, forthcoming.

[13] Chandrasekhar, Arun and Randall Lewis (2011), "Econometrics of Sampled Networks", mimeo, MIT.

[14] Cassan, Guilhem (2015), "Identity-Based Policies and Identity Manipulation: Evidence from Colonial Punjab", American Economic Journal: Economic Policy 7, 103-131.

[15] Chen, Daniel (2016), "The Deterrent Effect of the Death Penalty? Evidence from British Commutations During World War I", mimeo, TSE.

[16] Edlund, Lena, Hongbin Li, Junjian Yi, and Junsen Zhang (2013), "Sex Ratios and Crime: Evidence from China", Review of Economics and Statistics 95, 1520-1534.

[17] Ebenstein Avraham (2010), "The 'Missing Girls' of China and the Unintended Consequences of the One-Child Policy", Journal of Human Resources 45, 87-115.

[18] Fehr, Ernst and John List (2004), "The Hidden Costs and Returns of Incentives - Trust and Trustworthiness among CEOs", Journal of the European Economic Association 2, 743-71.

[19] Fernandez, Raquel and Alessandra Fogli (2006), "Fertility: The Role of Culture and Family Experience", Journal of the European Economic Association 4, 552-561.

[20] Fouka, Vasiliki (2019), "Backlash: the Unintended Effects of Language Prohibition in US Schools after World War I", Review of Economic Studies, forthcoming.

[21] Frijters, Paul, Robert Gregory, and Xin Meng (2013), "The Role of Rural Migrants in the Chinese Urban Economy", in Dustmann, Christian (ed.), Migration-Economic Change, Social Challenge, Oxford University Press. 
[22] Fryer, Roland (2007), "Guess Who's Been Coming to Dinner? Trends in Interracial Marriage over the 20th Century", Journal of Economic Perspectives 21, 71-90.

[23] Gneezy, Uri and Also Rustichini (2000), "A Fine is a Price", Journal of Legal Studies 29, $1-17$.

[24] Gneezy, Uri, Stehpen Meier, and Pedro Rey-Biel (2011), "When and Why Incentives (Don't) Work to Modify Behavior", Journal of Economic Perspectives 25, 1-21.

[25] Hasmath, Reza and Benjamin Ho (2015), "Job Acquisition, Retention, and Outcomes for Ethnic Minorities in Urban China", Eurasian Geography and Economics 56, 24-43.

[26] Horowitz, Donald (2000), Ethnic Groups in Conflict, University of California Press.

[27] Huang, Wei and Yi Zhou (2016), "Impact of One-Child Policy on Interethnic Marriage in China", mimeo, Harvard University.

[28] Jewitt, Ian (2004), "Notes on the Shape of Distributions", mimeo, Oxford University.

[29] Joensen, Juanna and Helena Skyt Nielsen (2015), "Spillover Effects in Educational Choice", Mimeo, IZA.

[30] Karing, Anne (2019), "Social Signaling and Childhood Immunization: A Field Experiment in Sierra Leone", Mimeo.

[31] Li, Xiaoxia (2008), "Xinjiang zujitonghun zinv minzurentong de diaochayufenxi" (Ethnic Identity of Children in Mixed Marriages in Xinjiang), available at http://www.sociologyol.org/yanjiubankuai/fenleisuoyin/fenzhishehuixue/shehuirenleixue/200812-04/6702.html

[32] Manski, Charles (1993), "Identification of Endogenous Social Effects: The Reflection Problem", Review of Economic Studies 60, 531-542.

[33] Nix, Emily and Nancy Qian (2015), "The Fluidity of Race: 'Passing' in the United States, 1880-1940", NBER working paper.

[34] Peng, Peiyun (ed.) (1996), Zhong Guo Ji Hua Sheng Yu Quan Shu (Encyclopedia of China's Family Planning Program), China Population Press.

[35] Vail, Leroy (1989), The Creation of Tribalism in Southern Africa, University of California Press. 


\section{Figure 1 Share of Children that Break the Norm (i.e., with Mother's Ethnicity) by Type of Mixed Marriage and Birth Cohort}

(a) Aggregate Data: Share of Children that Break the Norm

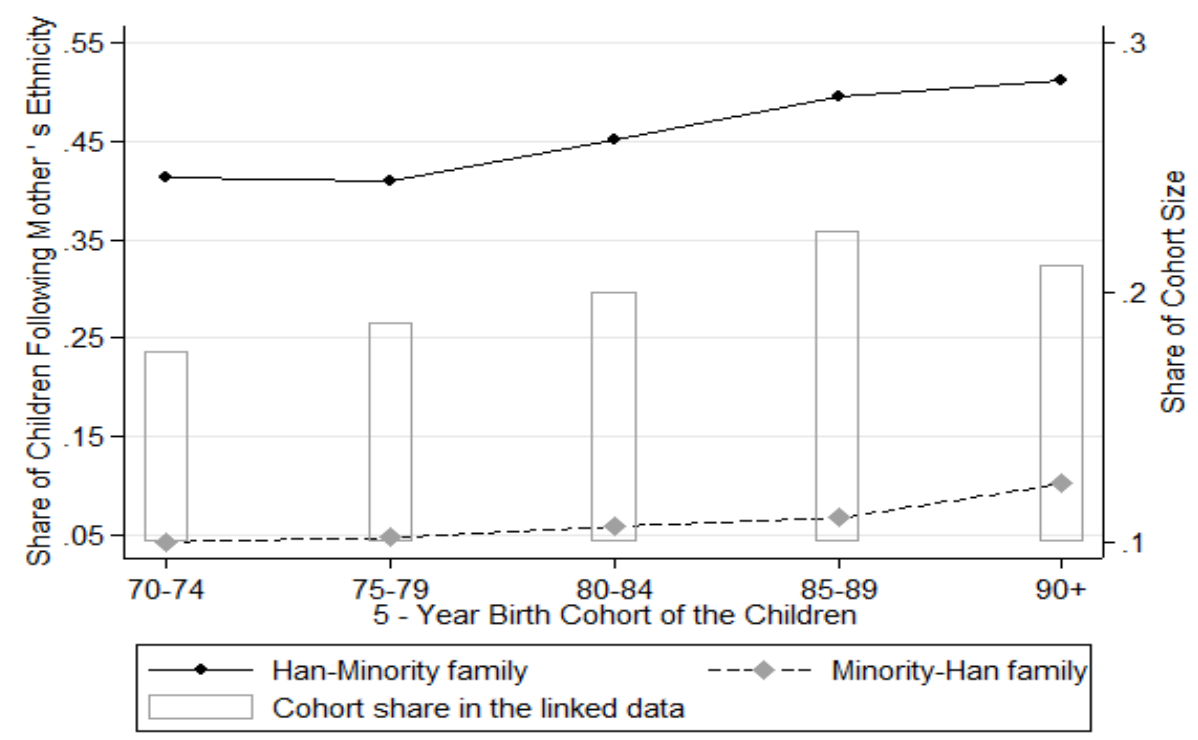

(b) Individual Data: Probability of Breaking the Norm

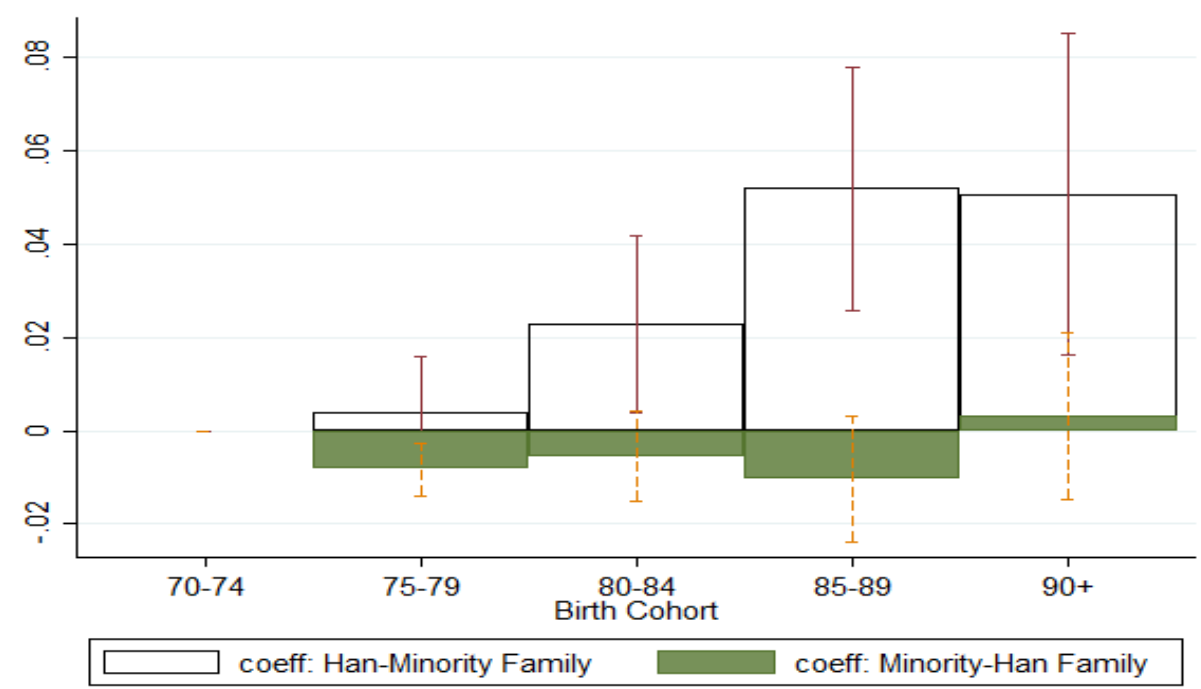

Notes: This figure shows two facts using aggregate and individual data: As in F1, children are more likely to have their mother's ethnicity in Han-Minority families; as in F2, an increasing share of children with their mother's ethnicity in Han-Minority families after 1980. Figure (b) visualizes the results in columns (3) and (6) of Appendix Table A.2. It shows the probability of having a minority child in two types of mixed marriages over time, using those born during 1970-74 as the comparison group. The bars indicate $95 \%$ confidence intervals. 
Figure 2 Distribution of the Share of Children with their Mother's Ethnicity in Mixed Marriages across Marriage Type and Prefectures (for those born in 1970-74)

(a) Share of Children with Mother's (Minority) Ethnicity in Han-Minority Marriages

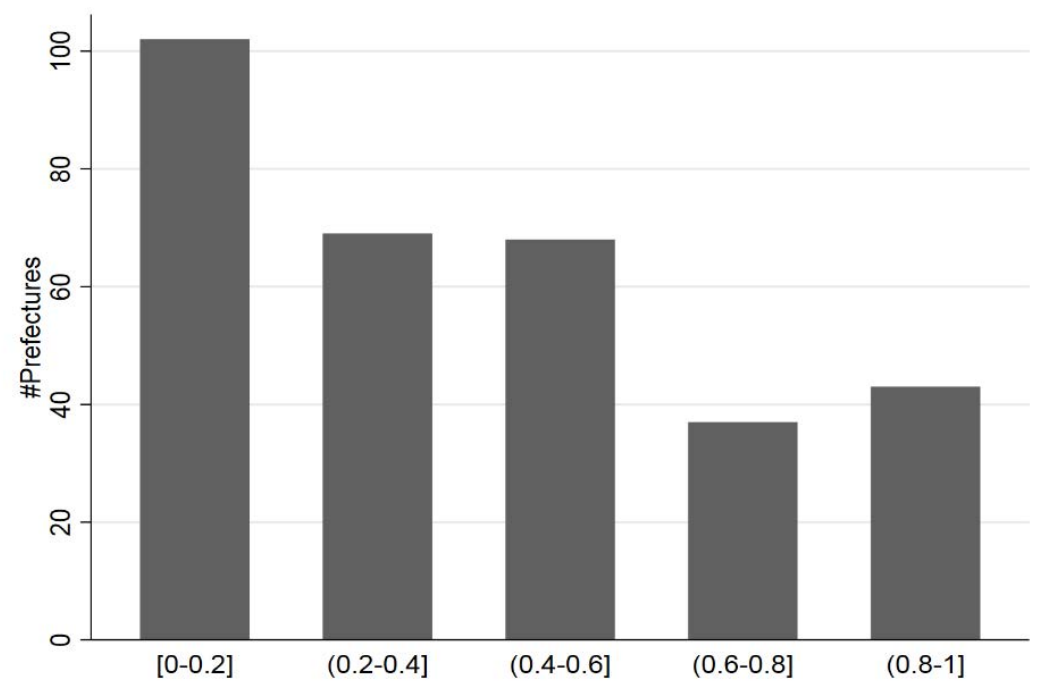

(b) Share of Children with Mother's (Han) Ethnicity in Minority-Han Marriages

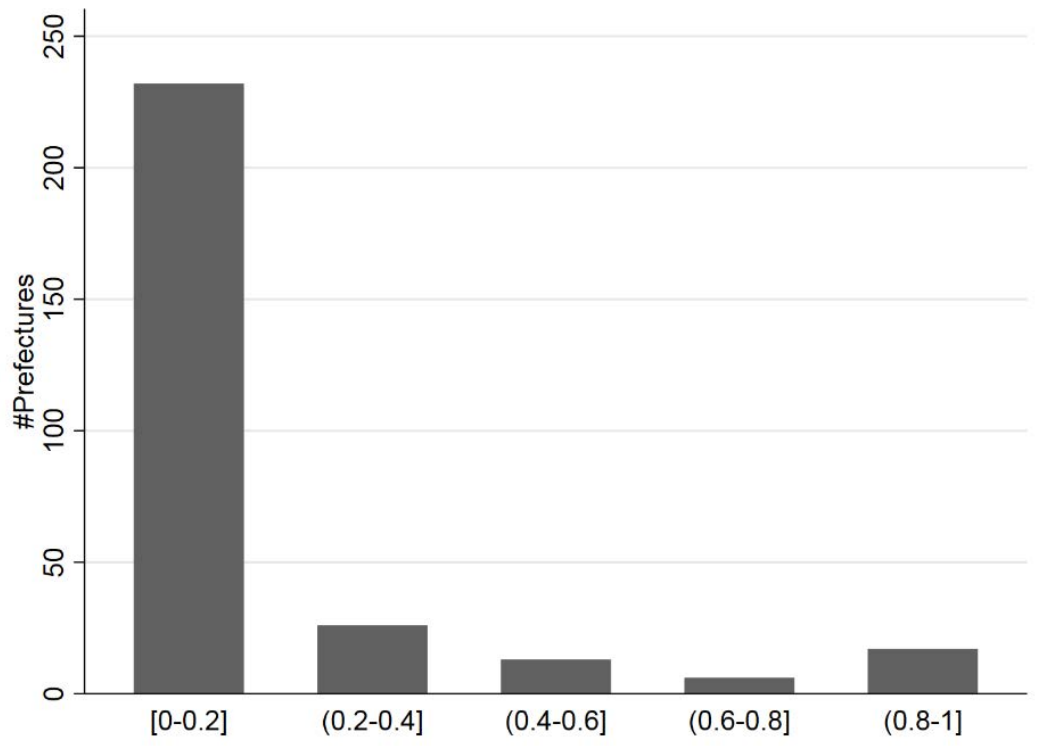

Notes: Panel (a) shows that the share of children with their mother's ethnicity varies a great deal across regions for Han-minority marriages. Panel (b) shows that the children of minority-Han couples in most prefectures rarely have their mother's ethnicity. Our empirical analysis focuses on Han-minority families. 
Figure 3 The Race between Honor and Stigma

(a) An illustration

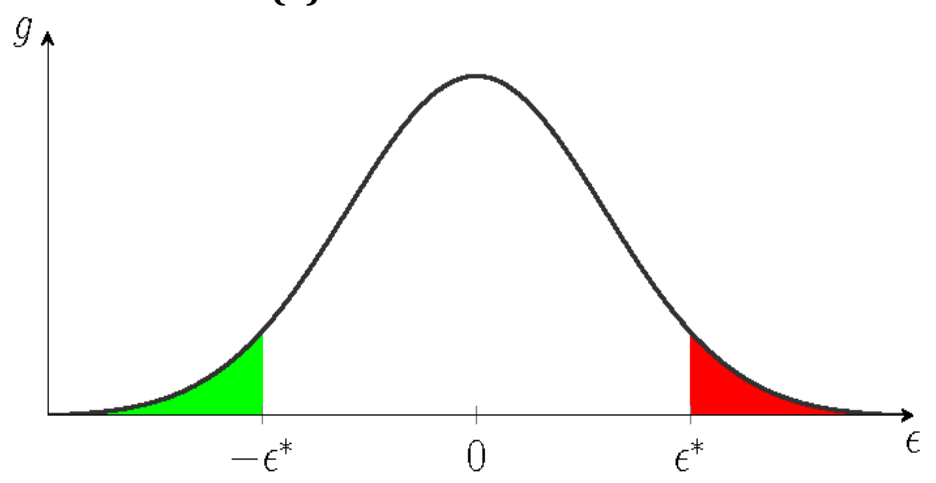

(b) A numerical example

Stigma and Honor

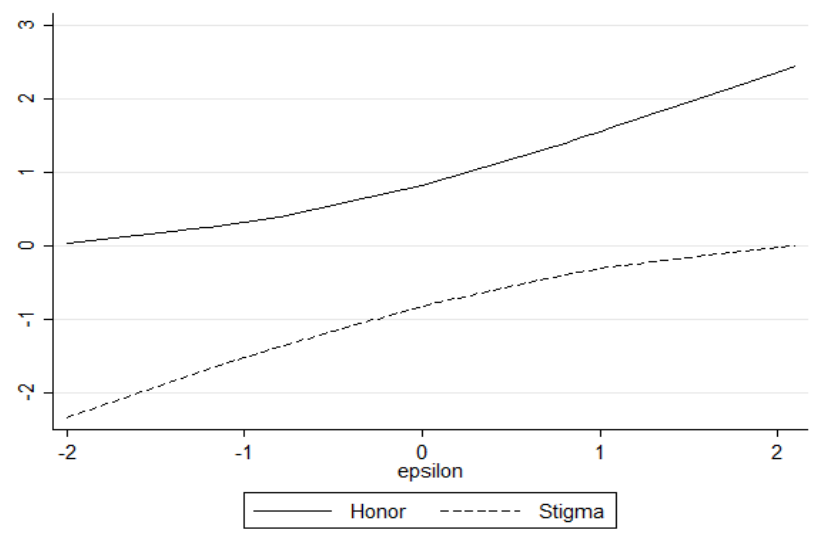

(c) $\Delta$ (= Honor-Stigma)

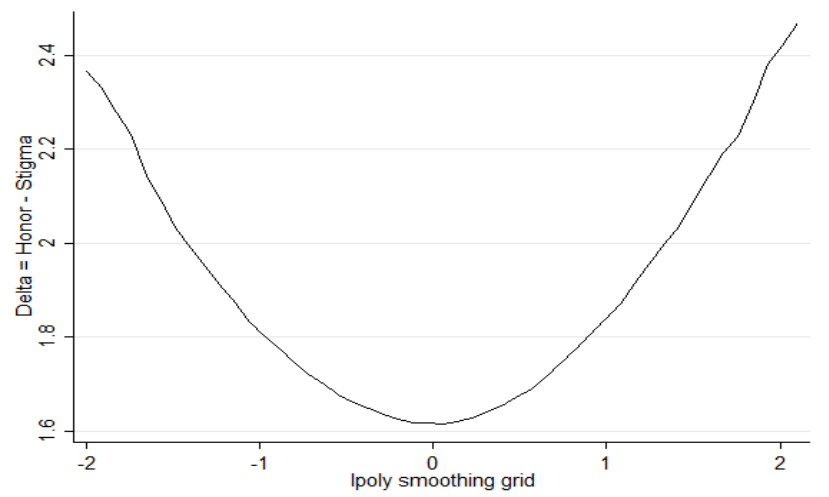

Notes: Panel (a) illustrates the social stigma (the green area) and the social honor (the non-green area) for a low equilibrium cutoff, and the stigma (non-red area) and the honor (the red area) for a high cutoff. Panel (c) illustrates how the gain in social reputation (Honor minus Stigma) has a minimum and changes with the equilibrium share of children breaking the norm (i.e. following the mother's ethnicity). The numerical example in panels (b) and (c) relies on the specific assumption that $\epsilon$ has a $(0,1)$ normal distribution. 
Figure 4 Spatial Variation in the Share of Children with Mother's Ethnicity in Hanminority Marriages (for those born in 1970-74)

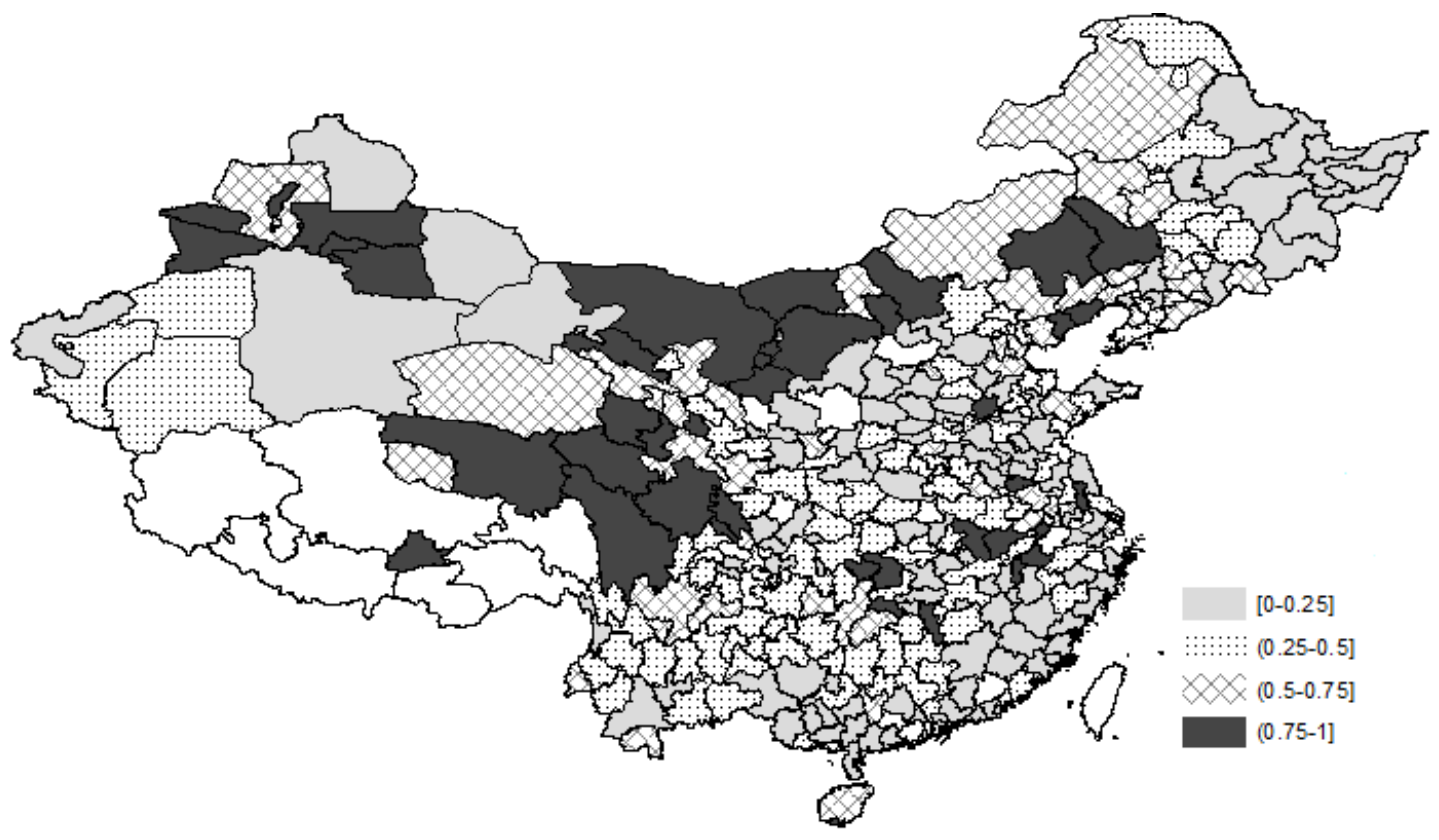

Notes: This figure maps the average probability of children with their mother's ethnicity born during 1970-74 in Han-minority families across prefectures. A set of province fixed effects explains about $36 \%$ of the variation across prefectures. Our empirical analysis exploits only within-province variation. We also control for province-by-year fixed effects to allow for flexible (non-parametric) time trends across provinces. 
Figure 5: The Dynamic Effects of Material Benefits $(b)$ * Social Motives on the Probability of Mixed-Marriage Children with their Mother's Ethnicity

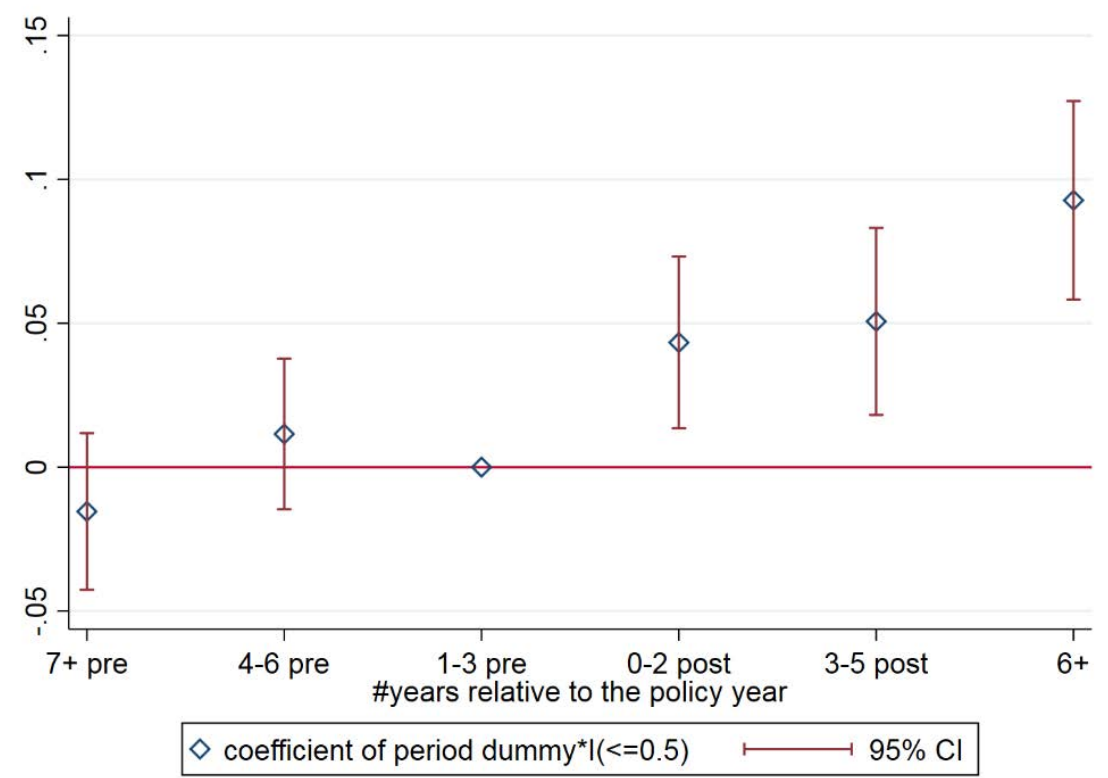

Notes: These figures plot the dynamic impacts of material benefits (measured by the rollout of family-planning policy) interacting with social motives (measured by the 1970-74 share of children with mother's ethnicity falling below a 0.5 cutoff). The reference period is 1-3 years before the introduction of the policy. The dimonds indicate the estimates in column (2) in Online Appendix C3 and the bars indicate 95\% confidence intervals. The figure shows that (1) there are no similar positive effects before the policy, and (2) the effect is increasing over time, which is consistent with the dynamic extension of the model in Online Appendix C4. 
Table 1: Summary Statistics

\begin{tabular}{lccc}
\hline & Mean & s.d. & \#Obs. \\
\multicolumn{1}{l}{ Minority Husband -- Han Wife (little variation) } & & \\
Child with Mother's Ethnicity & 0.063 & 0.242 & 110,020 \\
& & & \\
$\quad$ Han Husband -- Minority Wife (our focus) & & \\
a) Individual Characteristics & & & \\
Child with Mother's Ethnicity: All & 0.465 & 0.499 & 124,940 \\
Child with Mother's Ethnicity: Born before 1980 & 0.411 & 0.492 & 42,140 \\
Child with Mother's Ethnicity: Born after 1980 & 0.492 & 0.500 & 82,800 \\
Husband's education (1-4) & 2.094 & 0.616 & 124,940 \\
Wife's education (1-4) & 1.878 & 0.654 & 124,940 \\
Urban husband & 0.261 & 0.439 & 59,278 \\
Urban wife & 0.261 & 0.422 & 59,278
\end{tabular}

\section{b) Ethnic Benefits Measures (b)}

$\begin{array}{llll}\text { Post policy (rollout of family-planning) } & 0.581 & 0.493 & 121,908\end{array}$

$\begin{array}{lllll}\text { Lagged extra Minority fertility (for women aged 40+) } & 0.059 & 0.129 & 97,217\end{array}$

$\begin{array}{llll}\text { Extra exam scores (relative to cutoff score for colleges) } & 0.014 & 0.015 & 124,938\end{array}$

\section{c) Proxy for Intrinsic Costs (e)}

Son

Religious wife

$0.531 \quad 0.499 \quad 124,940$

$0.185 \quad 0.388 \quad 124,940$

\section{d) Prefecture Characteristics}

$\begin{array}{llll}\text { Minority prob. of those born in 1970-74 } & 0.388 & 0.310 & 319\end{array}$

$\begin{array}{llll}\text { Borderland } & 0.273 & 0.446 & 319\end{array}$

$\begin{array}{llll}\text { Minority pop. share in } 1982 & 13.295^{1} & 23.405 & 272\end{array}$

$\begin{array}{llll}\text { Share of pop. vith high school or above in } 1982 & 7.890 & 4.655 & 272\end{array}$

$\begin{array}{llll}\text { \#children for a minority in } 1982 \text { (women aged 40+) } & 5.255 & 1.279 & 261\end{array}$

Notes: This table reports the summary statistics for the key variables in our analysis. The table shows that there is little variation in the ethnic choices in minority-Han marriages. Our analysis in the paper focuses on Han-minority marriages.

\footnotetext{
${ }^{1}$ Note that the mean of prefecture-level shares is slightly different from the total minority population share (around 9\%).
} 
Table 2A Baseline Results for P1: The Impact of Material Benefits (b) and Social Motives on the Probability of Mixed-marriage Children with Mother's Ethnicity (Results using pre-post family planning policy to proxy material benefits $b$ )

Dependent Variable: Child with Mother's Ethnicity=0/1 (mean: 0.47)

\begin{tabular}{|c|c|c|c|c|c|c|}
\hline & (1) & $(2)$ & (3) & (4) & (5) & (6) \\
\hline $\mathrm{I}(\leq 0.5)^{*} b$ (Post Policy) & & $\begin{array}{c}0.072^{* * *} \\
(0.019) \\
{[0.030]}\end{array}$ & $\begin{array}{c}0.069 * * * \\
(0.019) \\
{[0.031]}\end{array}$ & $\begin{array}{c}0.071^{* * *} \\
(0.020) \\
{[0.031]}\end{array}$ & $\begin{array}{c}0.074^{* * *} \\
(0.022) \\
{[0.027]}\end{array}$ & $\begin{array}{c}0.070^{* * *} \\
(0.014) \\
{[0.024]}\end{array}$ \\
\hline$b$ (Post Policy) & $\begin{array}{c}0.078^{* * *} \\
(0.011) \\
{[0.019]}\end{array}$ & $\begin{array}{l}0.031 * * \\
(0.014) \\
{[0.014]}\end{array}$ & $\begin{array}{l}0.035^{* *} \\
(0.013) \\
{[0.013]}\end{array}$ & & & \\
\hline Prefecture FE & Y & Y & Y & Y & Y & Y \\
\hline Wife Ethnicity FE & & & Y & Y & Y & Y \\
\hline Birth Year FE & & & & Y & Y & Y \\
\hline Controls*b & & & & & Y & Y \\
\hline Province FE*Year FE & & & & & & Y \\
\hline Observations & 121,908 & 121,908 & 121,908 & 121,908 & 108,914 & 108,914 \\
\hline R-squared & 0.276 & 0.277 & 0.290 & 0.292 & 0.299 & 0.334 \\
\hline
\end{tabular}

Notes: This table shows the results using the provincial roll-out of family-planning polices to measure material benefits. The cutoff (0.5) is defined by the share of minority children in Han-minority families in the 1970-74 birth cohort. Controls include couples' charateristics (education-level fixed effects and 5-year birth-cohort fixed effects, for both husband and wife) and prefecture characteristics (listed in panel (d) of Table 1). The data come from three censuses and a mini census from 1982-2005. Standard errors in parentheses are clustered at the prefecture level, while those in brackets are clustered at the province level. Significance: $* * *, 1 \%, * *, 5 \%, *, 10 \%$. 
Table 2B Baseline Results for P1: The Impact of Material Benefits (b) and Social Motives on the Probability of Mixed-marriage Children with Mother's Ethnicity (with additional fertlity and additional exam scores for minorities proxying material benefits $b$ )

Dependent Variable: Child with Mother's Ethnicity=0/1 (mean: 0.47)

\begin{tabular}{|c|c|c|c|c|c|c|c|}
\hline & (1) & (2) & (3) & (4) & (5) & (6) & (7) \\
\hline $\mathrm{I}(\leq 0.5)^{*} b$ (Extra Fertility) & & $\begin{array}{c}0.027^{* * *} \\
(0.009)\end{array}$ & $\begin{array}{c}0.027^{* * *} \\
(0.009)\end{array}$ & & & & $\begin{array}{l}0.022^{* *} \\
(0.009)\end{array}$ \\
\hline$b$ (Extra Fertility) & $\begin{array}{c}0.034^{* * *} \\
(0.005)\end{array}$ & & & & & & \\
\hline $\mathrm{I}(\leq 0.5)^{*} b($ Extra Scores $)$ & & & & & $\begin{array}{c}0.052^{* * *} \\
(0.009)\end{array}$ & $\begin{array}{c}0.034^{* * *} \\
(0.009)\end{array}$ & $\begin{array}{c}0.022^{* * *} \\
(0.008)\end{array}$ \\
\hline$b$ (Extra Scores) & & & & $\begin{array}{c}0.044^{* * *} \\
(0.007)\end{array}$ & & & \\
\hline Prefecture FE & Y & Y & Y & Y & Y & Y & Y \\
\hline Wife Ethnicity FE & & Y & Y & & Y & Y & Y \\
\hline Birth Year FE & & Y & Y & & Y & Y & Y \\
\hline Controls $* b$ & & & Y & & & Y & Y \\
\hline Province FE*Year FE & & & Y & & & Y & Y \\
\hline Observations & 107,903 & 107,903 & 96,874 & 124,938 & 124,938 & 111,944 & 96,873 \\
\hline R-squared & 0.277 & 0.295 & 0.341 & 0.269 & 0.287 & 0.329 & 0.342 \\
\hline
\end{tabular}


Table 3 Results for P1': The Interaction Effects by Quartiles on the Probability of Mixed-marriage Children with Mother's Ethnicity

Dependent Variable: Child with Mother's Ethnicity=0/1 (mean: 0.47)

\begin{tabular}{|c|c|c|c|c|c|c|c|c|c|}
\hline \multirow{2}{*}{$\begin{array}{l}\text { Proxy for material benefits } b \\
\text { I }(0-0.25)^{*} b\end{array}$} & \multicolumn{3}{|c|}{$\begin{array}{l}(1) \quad(2) \\
\text { Rollout of Family Planning } \\
\text { Post Policy =0/1 }\end{array}$} & \multicolumn{3}{|c|}{$\begin{array}{l}\text { Extra Fertility for Minority } \\
\text { (lagged cohort) }\end{array}$} & \multicolumn{3}{|c|}{$\begin{array}{c}\text { Extra Exam Scores for Minority } \\
\text { (share of cutoff score) }\end{array}$} \\
\hline & $\begin{array}{l}0.097 * * * \\
(0.024)\end{array}$ & $\begin{array}{c}0.099 * * * \\
(0.023)\end{array}$ & $\begin{array}{c}0.094^{* * *} \\
(0.029)\end{array}$ & $\begin{array}{l}0.030^{* *} \\
(0.014)\end{array}$ & $\begin{array}{c}0.036^{* * *} \\
(0.013)\end{array}$ & $\begin{array}{c}0.032^{* * *} \\
(0.011)\end{array}$ & $\begin{array}{c}0.052^{* * *} \\
(0.016)\end{array}$ & $\begin{array}{c}0.058^{* * *} \\
(0.017)\end{array}$ & $\begin{array}{l}0.040^{* *} \\
(0.016)\end{array}$ \\
\hline $\mathrm{I}(0.25-0.5) * b$ & $\begin{array}{l}0.145^{* * *} \\
(0.027)\end{array}$ & $\begin{array}{c}0.144^{* * *} \\
(0.026)\end{array}$ & $\begin{array}{c}0.119 * * * \\
(0.027)\end{array}$ & $\begin{array}{l}0.044^{* *} \\
(0.017)\end{array}$ & $\begin{array}{c}0.041^{* * *} \\
(0.013)\end{array}$ & $\begin{array}{c}0.032^{* * *} \\
(0.009)\end{array}$ & $\begin{array}{c}0.077^{* * *} \\
(0.015)\end{array}$ & $\begin{array}{c}0.088^{* * *} \\
(0.016)\end{array}$ & $\begin{array}{c}0.063^{* * *} \\
(0.014)\end{array}$ \\
\hline $\mathrm{I}(0.5-0.75) * b$ & $\begin{array}{c}0.079^{* * *} \\
(0.025)\end{array}$ & $\begin{array}{c}0.080^{* * *} \\
(0.024)\end{array}$ & $\begin{array}{l}0.052^{*} \\
(0.027)\end{array}$ & $\begin{array}{c}0.032^{* * *} \\
(0.009)\end{array}$ & $\begin{array}{l}0.025^{* *} \\
(0.011)\end{array}$ & $\begin{array}{c}0.009 \\
(0.011)\end{array}$ & $\begin{array}{c}0.030 \\
(0.018)\end{array}$ & $\begin{array}{l}0.034^{* *} \\
(0.017)\end{array}$ & $\begin{array}{l}0.029^{*} \\
(0.016)\end{array}$ \\
\hline Prefecture FE & Y & Y & Y & Y & Y & Y & Y & Y & Y \\
\hline Wife Ethnicity FE & & Y & Y & & Y & Y & & Y & Y \\
\hline Birth Year FE & & Y & Y & & Y & Y & & Y & Y \\
\hline Controls* $b$ & & & Y & & & Y & & & Y \\
\hline Province FE * Year FE & & & Y & & & Y & & & Y \\
\hline$p$-value (2nd vs. 3 rd) & 0.014 & 0.019 & 0.000 & 0.514 & 0.219 & 0.048 & 0.003 & 0.000 & 0.0003 \\
\hline Observations & 121,908 & 121,908 & 108,914 & 107,903 & 107,903 & 96,874 & 124,938 & 124,938 & 111,944 \\
\hline R-squared & 0.278 & 0.293 & 0.334 & 0.277 & 0.296 & 0.341 & 0.270 & 0.288 & 0.329 \\
\hline
\end{tabular}

Notes: According to Prediction P1', the interaction effects of material benefits and social motives estimated for the first three quartiles should be larger than that for the fourth quartile. Further, the effect for the second quartile should be larger than that for the third quartile. Controls include couples' charateristics (education-level fixed effects and 5-year birth-cohort fixed effects, for both husband and wife) and prefecture characteristics (listed in panel (d) of Table 1). Standard errors are clustered at the prefecture evel. Significance: ${ }^{* * *}$, $1 \%, * *, 5 \%, *, 10 \%$. 
Table 4 Considering the Effects of Endogenous Marriages

(Dependent Variable: Child with Mother's Ethnicity=0/1)

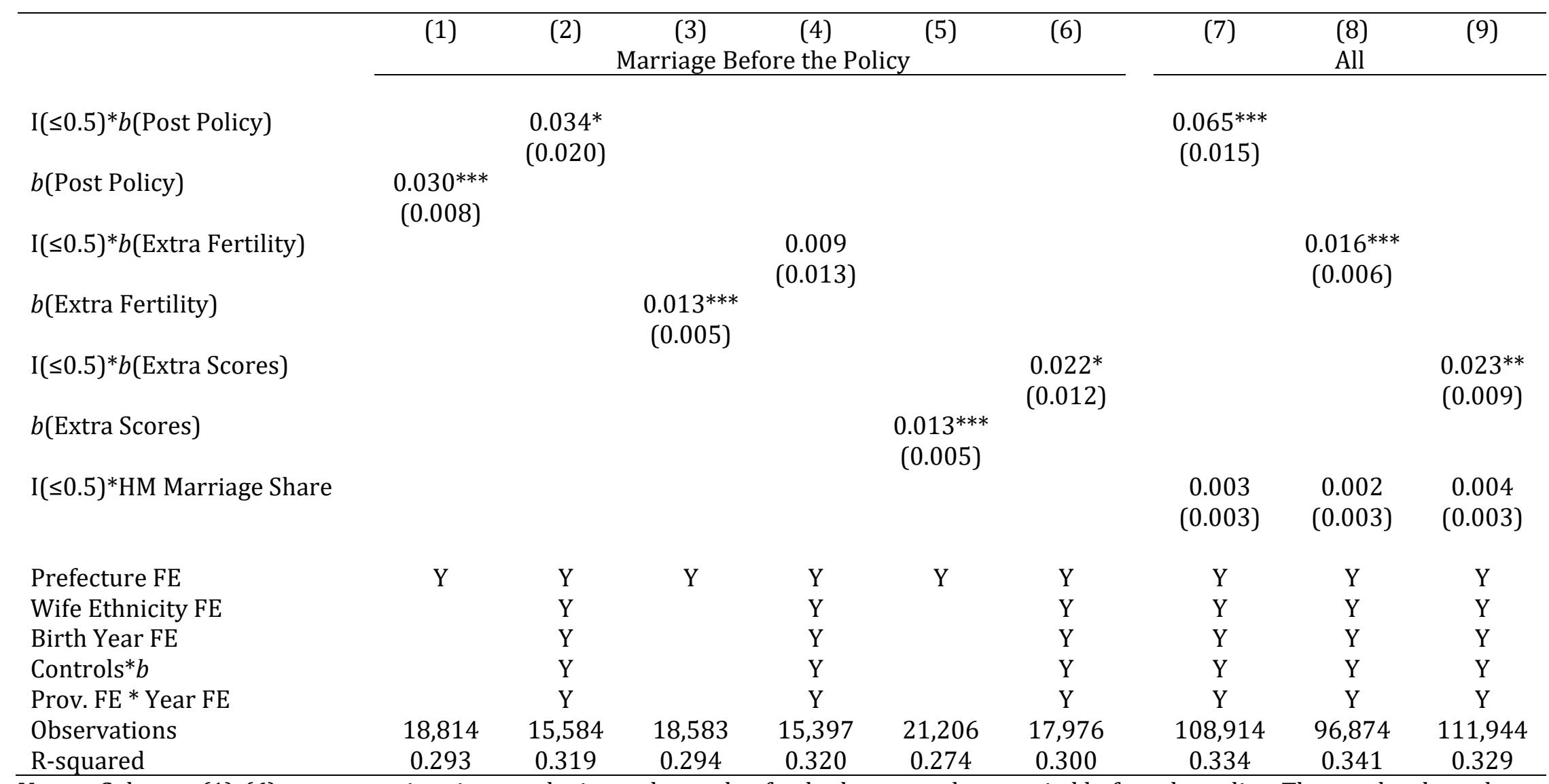

Notes: Columns (1)-(6) present estimation results in a subsample of only those couples married before the policy. The results show that the baseline pattern is robust to the concern of endogenous marriages. Controls include couples' charateristics (education level fixed effects and 5-year birth-cohort fixed effects, for both husband and wife) and prefecture characteristics (listed in panel (d) of Table 1). Standard errors are clustered at the prefecture level. Significance: ***, 1\%, **, 5\%, *, 10\%. 


\section{Table 5 Results Using Alternative Peer Groups}

Dependent Variable: Child with Mother's Ethnicity $=0 / 1$

\begin{tabular}{|c|c|c|c|c|c|c|}
\hline & $(1)$ & $(2)$ & (3) & (4) & (5) & (6) \\
\hline (a) & \multicolumn{3}{|c|}{ Rural (mean: 0.49) } & \multicolumn{3}{|c|}{ Urban (mean: 0.66) } \\
\hline $\mathrm{I}(\leq 0.5)^{*} b$ (Post Policy) & $\begin{array}{c}0.043^{*} \\
(0.023)\end{array}$ & & & $\begin{array}{r}0.121^{* * *} \\
(0.025)\end{array}$ & & \\
\hline $\mathrm{I}(\leq 0.5)^{*} b$ (Extra Fert.) & & $\begin{array}{r}0.032^{*}= \\
(0.009\end{array}$ & & & $\begin{array}{r}0.036^{* *} \\
(0.009\end{array}$ & \\
\hline $\mathrm{I}(\leq 0.5)^{*} b$ (Extra Score) & & & $\begin{array}{c}0.014 \\
(0.011)\end{array}$ & & & $\begin{array}{c}0.064^{* * *} \\
(0.020)\end{array}$ \\
\hline (b) & Below Higl & School & an: 0.44$)$ & $\underline{\text { Higl }}$ & $\mathrm{ool}+(\mathrm{m}$ & $0.60)$ \\
\hline $\mathrm{I}(\leq 0.5)^{*} b$ (Post Policy) & $\begin{array}{c}0.058^{* * *} \\
(0.014)\end{array}$ & & & $\begin{array}{r}0.071^{* * *} \\
(0.027)\end{array}$ & & \\
\hline $\mathrm{I}(\leq 0.5)^{*} b$ (Extra Fert.) & & $\begin{array}{r}0.024^{*} \\
(0.009\end{array}$ & & & $\begin{array}{r}0.021 \\
(0.015\end{array}$ & \\
\hline $\mathrm{I}(\leq 0.5)^{*} b$ (Extra Score) & & & $\begin{array}{c}0.027^{* * *} \\
(0.009)\end{array}$ & & & $\begin{array}{c}0.037 \\
(0.023)\end{array}$ \\
\hline (c) & By Precise & Ethnicit & the Wife & (a) 1 & unty (a & ounty FEs) \\
\hline $\mathrm{I}(\leq 0.5)^{*} b$ (Post Policy) & $\begin{array}{c}0.106^{* * *} \\
(0.015)\end{array}$ & & & $\begin{array}{r}0.150^{* * *} \\
(0.019)\end{array}$ & & \\
\hline $\mathrm{I}(\leq 0.5)^{*} b$ (Extra Fert.) & & $\begin{array}{r}0.045^{*} \\
(0.008\end{array}$ & & & $\begin{array}{c}0.099^{*} \\
(0.013\end{array}$ & \\
\hline $\mathrm{I}(\leq 0.5)^{*} b$ (Extra Score) & & & $\begin{array}{c}0.046^{* * *} \\
(0.007)\end{array}$ & & & $\begin{array}{c}0.098^{* * *} \\
(0.019)\end{array}$ \\
\hline (e) & $\underline{\text { Using }}$ & $\mathrm{HM}-\mathrm{MH}$ & families & & & \\
\hline $\mathrm{I}(\leq 0.5)^{*} b$ (Post Policy) & $\begin{array}{c}0.080^{* * *} \\
(0.025)\end{array}$ & & & & & \\
\hline $\mathrm{I}(\leq 0.5)^{*} b($ Extra Ferti $)$ & & $\begin{array}{l}0.012 \\
(0.007\end{array}$ & & & & \\
\hline $\mathrm{I}(\leq 0.5)^{*} b$ (Extra Score) & & & $\begin{array}{c}0.039^{* * *} \\
(0.012)\end{array}$ & & & \\
\hline Pref FE, Birth YearFE & Y & $\mathrm{Y}$ & Y & Y & Y & Y \\
\hline Wife Ethnicity FE & Y & Y & Y & Y & Y & Y \\
\hline Controls* $b$ & $\mathrm{Y}$ & $\mathrm{Y}$ & $\mathrm{Y}$ & $\mathrm{Y}$ & $\mathrm{Y}$ & $\mathrm{Y}$ \\
\hline Prov. FE * Year FE & $\mathrm{Y}$ & $\mathrm{Y}$ & $\mathrm{Y}$ & $\mathrm{Y}$ & $\mathrm{Y}$ & $\mathrm{Y}$ \\
\hline
\end{tabular}

Notes: This table shows that the baseline results hold up under alternative definitions of peer groups. Panel (a) separates rural/urban couples based on the 2000 and 2005 censuses; panels (b) and (c) define peer groups relevant for social reputation by education and minority groups; panel (d) define peer groups by county; and panel (e) defines these peer groups as all families that can choose to give their children the mother's ethnicity, a choice which cannot be made by same-ethnicity couples. Controls include couples' charateristics (education level fixed effects and 5-year birth-cohort fixed effects, for both husband and wife) and prefecture characteristics (listed in panel (d) of Table 1). 